\title{
Functional Connectome Analysis of Dopamine Neuron Glutamatergic Connections in Forebrain Regions
}

\author{
DSusana Mingote, ${ }^{1}$ Nao Chuhma, ${ }^{1}$ Sheila V. Kusnoor, ${ }^{2}{ }^{\circledR}$ Bianca Field, ${ }^{1}$ Ariel Y. Deutch, ${ }^{2}$ and ${ }^{\oplus S t e p h e n ~ R a y p o r t ~}{ }^{1}$ \\ ${ }^{1}$ Department of Psychiatry, Columbia University, and Department of Molecular Therapeutics, NYS Psychiatric Institute, New York, New York 10032, and \\ 2Departments of Psychiatry and Pharmacology, Vanderbilt University Medical Center, Nashville, Tennessee 37232
}

In the ventral tegmental area (VTA), a subpopulation of dopamine neurons express vesicular glutamate transporter 2 and make glutamatergic connections to nucleus accumbens (NAc) and olfactory tubercle (OT) neurons. However, their glutamatergic connections across the forebrain have not been explored systematically. To visualize dopamine neuron forebrain projections and to enable photostimulation of their axons independent of transmitter status, we virally transfected VTA neurons with channelrhodopsin-2 fused to enhanced yellow fluorescent protein (ChR2-EYFP) and used DAT ${ }^{\text {IREScre }}$ mice to restrict expression to dopamine neurons. ChR2-EYFP-expressing neurons almost invariably stained for tyrosine hydroxylase, identifying them as dopaminergic. Dopamine neuron axons visualized by ChR2-EYFP fluorescence projected most densely to the striatum, moderately to the amygdala and entorhinal cortex (ERC), sparsely to prefrontal and cingulate cortices, and rarely to the hippocampus. Guided by ChR2-EYFP fluorescence, we recorded systematically from putative principal neurons in target areas and determined the incidence and strength of glutamatergic connections by activating all dopamine neuron terminals impinging on recorded neurons with wide-field photostimulation. This revealed strong glutamatergic connections in the NAc, OT, and ERC; moderate strength connections in the central amygdala; and weak connections in the cingulate cortex. No glutamatergic connections were found in the dorsal striatum, hippocampus, basolateral amygdala, or prefrontal cortex. These results indicate that VTA dopamine neurons elicit widespread, but regionally distinct, glutamatergic signals in the forebrain and begin to define the dopamine neuron excitatory functional connectome.

Key words: cotransmission; entorhinal cortex; glutamate; nucleus accumbens; optogenetics

\section{Significance Statement}

Dopamine neurons are important for the control of motivated behavior and are involved in the pathophysiology of several major neuropsychiatric disorders. Recent studies have shown that some ventral midbrain dopamine neurons are capable of glutamate cotransmission. With conditional expression of channelrhodopsin in dopamine neurons, we systematically explored dopamine neuron connections in the forebrain and identified regionally specific dopamine neuron excitatory connections. Establishing that only a subset of forebrain regions receive excitatory connections from dopamine neurons will help to determine the function of dopamine neuron glutamate cotransmission, which likely involves transmission of precise temporal signals and enhancement of the dynamic range of dopamine neuron signals.

\section{Introduction}

Dopamine neurons in the ventral tegmental area (VTA) project widely to forebrain targets (Swanson, 1982; Björklund and Dun-

Received April 27, 2015; revised Oct. 9, 2015; accepted Nov. 10, 2015.

Author contributions: S.M., N.C., A.Y.D., and S.R. designed research; S.M., N.C., S.V.K., and B.F. performed research; S.V.K. and B.F. contributed unpublished reagents/analytic tools; S.M., N.C., S.V.K., B.F., A.Y.D., and S.R. analyzed data; S.M., N.C., A.Y.D., and S.R. wrote the paper.

This work was supported by the Brain \& Behavior Research Foundation (NARSAD Young Investigator Award to S.M.), NIH (Grants MH087758 and DA038966 to S.R., and MH077298 to A.Y.D.), and the Confocal and Specialized Microscopy Shared Resource of the Herbert Irving Comprehensive Cancer Center at Columbia University, which is supported by the NIH (Grant P30 CA013696). We thank Celia Gellman for technical assistance, Karl Deisseroth for the DI0-ChR2-EYFP construct, Jennifer Kelly Shepphird for editorial advice, and Abigail Kalmbach and Leora Yetnikoff for their comments on the manuscript.

The authors declare no competing financial interests. nett, 2007; Yetnikoff et al., 2014), where they regulate aspects of motivation, learning, habit formation, and social behavior (Zweifel et al., 2009; Wang et al., 2011; Salamone and Correa, 2012; Gunaydin et al., 2014) and are involved in neuropsychiatric disorders including addiction, depression, and schizophrenia (Lüscher and Malenka, 2011; Kuepper et al., 2012; Everitt and Robbins, 2013). Some VTA dopamine neurons express vesicular glutamate transporter 2 (VGLUT2) and corelease glutamate (Sulzer et al., 1998; Chuhma et al., 2004; Dal Bo et al., 2004;

Correspondence should be addressed to Dr. Stephen Rayport, Columbia Psychiatry/Molecular Therapeutics, 1051 Riverside Drive, Unit 62, New York, NY 10032. E-mail: stephen.rayport@columbia.edu. DOI:10.1523/JNEUROSCI.1674-15.2015

Copyright $\odot 2015$ the authors $\quad 0270-6474 / 15 / 3516259-13 \$ 15.00 / 0$ 
Hnasko et al., 2010; Stuber et al., 2010; Tecuapetla et al., 2010; Taylor et al., 2014; Trudeau et al., 2014) or GABA (Tritsch et al., 2012). Although in situ hybridization studies in the rat have shown that $30-50 \%$ of VTA dopamine neurons identified by tyrosine hydroxylase (TH) immunoreactivity express VGLUT2 mRNA (Kawano et al., 2006; Yamaguchi et al., 2011; Morales and Root, 2014), fewer TH-VGLUT2-colocalized cells have been reported in the mouse (Yamaguchi et al., 2015). However, 50\% of VTA dopamine neurons have been shown to express VGLUT2 using a conditional mCherry reporter virus in VGLUT2 ${ }^{\text {IREScre }}$ mice (Taylor et al., 2014), suggesting that similar numbers of dopamine neurons in the rat and mouse are capable of glutamate cotransmission. In contrast to the VTA, almost no substantia nigra (SN) dopamine neurons express VGLUT2 (Kawano et al., 2006; Mendez et al., 2008; Bérubé-Carrière et al., 2009; Yamaguchi et al., 2011; Yamaguchi et al., 2015). Consistent with the expression of VGLUT2 in VTA but not SN dopamine neurons, optogenetic activation of dopamine neuron terminals in the ventral striatum (vStr) [i.e., the nucleus accumbens (NAc) and olfactory tubercle (OT)] elicits excitatory responses, whereas activation of dopamine neuron terminals in the dorsal striatum (dStr; i.e., caudate-putamen) elicits very weak or no responses (Stuber et al., 2010; Tecuapetla et al., 2010; Tritsch et al., 2012; Ishikawa et al., 2013; Adrover et al., 2014; Chuhma et al., 2014; Wieland et al., 2014).

VTA dopamine neurons project widely to forebrain regions (Swanson, 1982; Taylor et al., 2014; Yetnikoff et al., 2014), but their glutamatergic synaptic connections beyond striatal sites have not been described. Although glutamatergic markers have been identified in dopaminergic forebrain projections (Yamaguchi et al., 2011; Gorelova et al., 2012; Busse and Smith, 2013; Taylor et al., 2014), it is not clear whether these projections make glutamatergic connections uniformly. We therefore used optogenetics to determine the incidence and strength of dopamine neuron glutamatergic connections in forebrain projection targets of the VTA. We used DAT ${ }^{\text {IREScre }}$ mice to restrict expression of ChR2-EYFP to DA neurons. ChR2-EYFP was robustly exported to dopamine neuron axons independent of transmitter or cotransmitter status (Tsai et al., 2009; Cohen et al., 2012; Chuhma et al., 2014; Lammel et al., 2015). Guided by axonal fluorescence, we systematically recorded dopamine neuron glutamatergic inputs to putative principal neurons in forebrain projection areas to determine the VTA dopamine neuron glutamatergic functional connectome.

\section{Materials and Methods}

Animals. We used heterozygous DAT-internal ribosome entry site (IRES)-cre recombinase (DAT ${ }^{\text {IREScre }}$ ) mice on a C57BL6J background (Bäckman et al., 2006) (jaxmice.jax.org/strain/006660.html). All studies were conducted in accordance with the guidelines of the National Institute of Health's Guide for the Care and Use of Laboratory Animals under protocols approved by the Institutional Animal Care and Use Committees of Columbia University and New York State Psychiatric Institute.

Viral expression of ChR2 in dopamine neurons. We used a serotype 5, replication-incompetent, adeno-associated virus (AAV) to drive credependent expression of ChR2-EYFP (Atasoy et al., 2008; Tsai et al., 2009). The ChR2-EYFP construct with double-floxed inverted open reading frame (DIO) (EF1 $\alpha$-DIO-hChR2(H134R)-EYFP) was packaged in an AAV vector (Gene Therapy Vector Core Facility, University of North Carolina). Mice between 25 and $40 \mathrm{~d}$ old were anesthetized with ketamine $(90 \mathrm{mg} / \mathrm{kg})+$ xylazine $(7 \mathrm{mg} / \mathrm{kg})$ and $1 \mu \mathrm{l}$ of virus (titer $1.5 \times$ $10^{12}$ genome copies $/ \mathrm{ml}$ ) was injected bilaterally into the VTA (AP -3.3 $\mathrm{mm}, \mathrm{DV}-4.3 \mathrm{~mm}, \mathrm{~L} \pm 0.5 \mathrm{~mm}$ relative to bregma). The virus was injected through glass pipettes (PCR micropipettes; Drummond) pulled to a tip diameter of $20-40 \mu \mathrm{m}$ with timed solenoid-controlled pulses of compressed air. Pipettes were left in place for $3 \mathrm{~min}$ after the injection to reduce back flux along the injection track.

Brain tissue preparation and immunohistochemistry. We used a total of 12 mice for morphological studies. At 3-5 weeks after injection, mice (males and females, 59-70 d of age) were anesthetized and then rapidly perfused intracardially with $1 \mathrm{ml}$ of warm phosphate buffer $\left(30^{\circ} \mathrm{C}, 0.1 \mathrm{M}\right.$, pH 7.4) containing 10,000 IU heparin/L, followed by $5 \mathrm{ml}$ of cold phosphate buffer and then by $5 \mathrm{ml}$ of $4 \%$ paraformaldehyde in phosphate buffer. Brains were removed and postfixed for 1 or $2 \mathrm{~d}$ at $4^{\circ} \mathrm{C}$. Brains were cryoprotected in $30 \%$ sucrose and then cut on a freezing microtome at 40 $\mu \mathrm{m}$ or cut without cryoprotection on a vibrating microtome at $50 \mu \mathrm{m}$. Coronal slices were collected into a cryoprotectant solution $(30 \%$ glycerol, $30 \%$ ethylene glycol in $0.1 \mathrm{~m}$ Tris $\mathrm{HCl}[\mathrm{pH} 7.4]$ ) and kept at $-20^{\circ} \mathrm{C}$ until processing.

Immunofluorescence methods were used to reveal immunoreactivity (ir) for ChR2-EYFP and TH; immunoperoxidase methods were used to reveal ChR2-EYFP-ir and NeuN-ir elements, as described previously (Bubser et al., 2000; Chuhma et al., 2014). Briefly, for immunofluorescence studies, sections were blocked with normal donkey serum and then incubated overnight with a rabbit polyclonal directed against green fluorescence protein (GFP), which recognizes EYFP (1:2000; Millipore AB3080) and mouse monoclonal anti-TH (1:1600; Immunostar 22941 or 1:5000; Millipore MAB318) antibodies. The next day, sections were washed and incubated for $2 \mathrm{~h}$ with anti-rabbit Alexa Fluor 488 (1:200; Invitrogen A-21206) and either anti-mouse Cy3 or Alexa Fluor 594 secondary antibodies (1:200; Invitrogen M30010 and A-21203, respectively). Sections were mounted on slides and coverslipped using Prolong Gold mounting medium (Invitrogen) and kept at $4^{\circ} \mathrm{C}$ before imaging.

For immunoperoxidase studies, sections were first incubated overnight in the rabbit polyclonal anti-GFP antibody (1:2000; Millipore AB3080) and, after washing, placed in biotinylated anti-rabbit IgG. Sections were then incubated in streptavidin-conjugated peroxidase and developed with cobalt chloride/nickel ammonium sulfate-intensified peroxidase to yield blue-black ChR2-EYFP ${ }^{+}$elements. To visualize NeuN-ir neurons, sections were washed, incubated in methanolic peroxide, washed, and incubated overnight in mouse monoclonal anti-NeuN antibody (1:1000; Millipore MAB377). Sections were then incubated in biotinylated anti-mouse IgG, washed, incubated in streptavidinconjugated peroxidase, and developed in peroxidase without heavy metal intensification to yield brown $\mathrm{NeuN}^{+}$nuclei.

Confocal image analysis. Confocal imaging was done using either a Fluoview FV1000 (Olympus) or A1 (Nikon) confocal scanning microscope. Fluorescence images used to quantify ChR2-EYFP/TH colocalization in the medial and lateral portions of the VTA and SN were acquired systematically along the AP axis at $-3.16 \mathrm{~mm},-3.28 \mathrm{~mm},-3.52 \mathrm{~mm}$, $-3.80 \mathrm{~mm},-3.88 \mathrm{~mm}$, and $-4.04 \mathrm{~mm}$ posterior to bregma. In each location, confocal photomicrograph stacks $(60 \times$ oil objective; optical zoom $1.4 \times$, and $z$-step increment $0.42 \mu \mathrm{m} ; 800 \times 800$ pixels image frames with a pixel size of $0.189 \mu \mathrm{m}^{2}$ ) were taken through the entire tissue section (40-60 images). After acquisition, confocal stacks were adjusted linearly for contrast and brightness using ImageJ version 64 (Abramoff et al., 2004). Counting of colocalized cells was done using the ImageJ version 64 cell-counter plug-in. All cells with a visible nucleus were counted within the counting frame through the entire thickness of the section. Numbers of ChR2-EYFP ${ }^{+} / \mathrm{TH}^{+}$cells in the VTA and SN were expressed as percentage of $\mathrm{TH}^{+}$cells counted at each stereotaxic location. Differences along the anterior-posterior and medial-lateral axes were analyzed using the nonparametric Friedman's test, with significance set at 0.05 .

To determine the density of ChR2-EYFP ${ }^{+}$axons in forebrain regions, we acquired 2 confocal stacks of 10 images ( $20 \times$ objective; optical zoom $1.4 \times$, and a $z$-step increment of $0.50 \mu \mathrm{m} ; 1024 \times 1024$ pixels image frames with pixel size $0.196 \mu \mathrm{m}^{2}$ ) for each forebrain area in approximately the same location where in vitro recordings were made independently of fluorescence brightness. In addition, we took a picture of an area without ChR2-EYFP fluorescence to normalize all images to the 
same background level. To access the density of ChR2-EYFP ${ }^{+}$axons, the $z$-projected, background-normalized, 8-bit images were made binary and the number of foreground pixels were counted using the histogram function in ImageJ version 64. The density of ChR2-EYFP ${ }^{+}$axons in forebrain areas was expressed as the number of suprathreshold pixels in the $1024 \times 1024$ pixel image frame. Differences in axonal density between forebrain regions were analyzed using one-way ANOVA and Scheffe post hoc test. Pixel densities are expressed as the mean \pm SEM. All statistical analyses were done using SPSS 22 (IBM).

Slice patch-clamp recording. We used 12 male and 17 female mice (54-83 d old, 21-56 d after AAV injections) for patch-clamp recordings. Animals were anesthetized with ketamine + xylazine. Brains were removed into ice-cold high-glucose artificial CSF (aCSF) saturated with carbogen $\left(95 \% \mathrm{O}_{2}+5 \% \mathrm{CO}_{2}\right)$. The composition of the high-glucose aCSF contained the following (in $\mathrm{mm}$ ): $75 \mathrm{NaCl}, 2.5 \mathrm{KCl}, 26 \mathrm{NaHCO}_{3}$, $1.25 \mathrm{NaH}_{2} \mathrm{PO}_{4}, 0.7 \mathrm{CaCl}_{2}, 2 \mathrm{MgCl}_{2}$, and 100 glucose adjusted to $\mathrm{pH} 7.4$. Coronal slices $(300 \mu \mathrm{m})$ were cut on a vibrating microtome (VT1200S; Leica) and recordings were done in five different coronal sections containing the striatum, the amygdala, the hippocampal formation, or the anterior cortices.

Slices were preincubated in high-glucose aCSF saturated with carbogen for $1 \mathrm{~h}$ at room temperature for recovery and then transferred to the recording chamber (submerged, $500 \mu$ l volume) on the stage of an Olympus BX61WI fluorescence microscope with a $60 \times$ water-immersion lens. The recording chamber was continuously perfused $(1.5 \mathrm{ml} / \mathrm{min})$ with standard aCSF containing the following (in $\mathrm{mm}$ ): $125 \mathrm{NaCl}, 2.5 \mathrm{KCl}, 25$ $\mathrm{NaHCO}_{3}, 1.25 \mathrm{NaH}_{2} \mathrm{PO}_{4}, 2 \mathrm{CaCl}_{2}, 1 \mathrm{MgCl}_{2}$, and 25 glucose, $\mathrm{pH} 7.4$, saturated with carbogen. Recordings were done at $31-33^{\circ} \mathrm{C}$ (TC $344 \mathrm{~B}$ temperature controller; Warner Instruments). Glutamatergic responses were isolated by the addition of a mixture of antagonists to the perfusate:

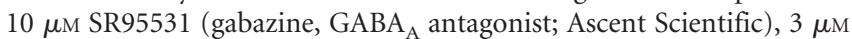
CGP55345 (GABA ${ }_{B}$ antagonist; Tocris Bioscience), $10 \mu \mathrm{M} \mathrm{SCH} 23390$ (D1 antagonist; Tocris Bioscience), $10 \mu \mathrm{M}(-)$-sulpiride (D2 antagonist; Tocris Bioscience), and $1 \mu \mathrm{M}$ scopolamine (muscarinic antagonist; Tocris Bioscience). Patch pipettes $(4-8 \mathrm{M} \Omega$ ) were fabricated with a P80/PC puller (Sutter Instruments) from standard borosilicate glass capillaries with filament (World Precision Instruments). The standard intracellular solution contained the following (in $\mathrm{mM}$ ): $140 \mathrm{Cs}^{+}$-gluconate, 10 HEPES, $0.1 \mathrm{CaCl}_{2}, 2 \mathrm{MgCl}_{2}, 1$ EGTA, 2 ATP-Na $\mathrm{Na}_{2}$, and $0.1 \mathrm{GTP}-\mathrm{Na}_{2}, \mathrm{pH}$ 7.3. The $\mathrm{Na}^{+}$-channel blocker lidocaine $N$-ethyl bromide (QX-314, 5 mM; Sigma-Aldrich) was added to the intracellular solution to block active currents. Voltage-clamp recordings were performed with an Axopatch 200B (Molecular Devices). Holding potential was $-75 \mathrm{mV}$. Given the small amplitude of EPSCs in some brain regions, series resistance $(18-40 \mathrm{M} \Omega$ ) was not compensated to minimize background noise. Liquid junction potentials $(\sim 15 \mathrm{mV})$ were adjusted online. Data acquisition commenced 5 min after achieving whole-cell mode to allow for diffusion of intracellular solution in recorded cells. Data were acquired and analyzed using Axograph X (Axograph Scientific) running on a PowerMac G4 (Apple). Data were filtered at $5 \mathrm{kHz}$ with a 4-pole Bessel filter and digitized (ITC-18 Interface; ALA Scientific Instruments) at $200 \mu \mathrm{s}$ intervals.

All recordings were done in projection regions with ChR2-EYFP ${ }^{+}$ axons, except in the CA1 region of the hippocampus, where ChR2$\mathrm{EYFP}^{+}$axons were extremely rare. Neurons chosen for recording were identified based on cell body location, size, and shape (with the $\mathrm{Cs}^{+}$based pipette solution including QX-314, neuronal firing patterns were not recorded). Synaptic responses were evoked by short flashes ( $5 \mathrm{~ms}$ at $0.1 \mathrm{~Hz}$ ) of a high-power blue LED (470 nm; Thorlabs). Glutamatergic responses were confirmed by perfusion of $40 \mu \mathrm{M}$ 6-cyano-7nitroquinoxaline-2,3-dione (CNQX; Tocris Bioscience) for at least one cell in each region.

The peak amplitudes of EPSCs were measured in a $50 \mathrm{~ms}$ postphotostimulation time window from the average of 10 consecutive traces. The detection threshold for determination of connections was set to the mean plus 2 SDs of the baseline (including spontaneous EPSCs) amplitude in the $100 \mathrm{~ms}$ time window preceding the photostimulation. When the peak amplitude of postphotostimulation EPSCs exceeded the detection threshold, the cell was counted as having received a dopamine neuron glutamatergic connection. Unless otherwise noted, data are reported as mean \pm SEM.

\section{Results}

\section{ChR2-EYFP virus injected into the VTA specifically transduced VTA dopamine neurons}

We visualized dopamine neurons and their projections by injection of AAV-DIO-ChR2-EYFP into the VTA of DAT ${ }^{\text {IREScre mice }}$ $(n=12)$. At 3-5 weeks after injection, we examined the distribution of ChR2-EYFP ${ }^{+}$cells in the ventral midbrain using immunofluorescence ( $n=4$ mice) and immunoperoxidase staining ( $n=4$ mice) (Fig. 1 ) and measured axonal projection density ( $n=4$ mice). All mice received bilateral viral injections in the VTA; in most cases, ChR2-EYFP ${ }^{+}$cells extended from the VTA through the medial half of SN on both sides (Fig. $1 A$, top); in two mice, the virus did not spread to the SN bilaterally, but even in those cases, ChR2-EYFP ${ }^{+}$cells were seen in the VTA bilaterally (Fig. 1A, bottom). We found that ChR2-EYFP ${ }^{+}$cells overlapped completely with $\mathrm{TH}^{+}$cells (Fig. $1 B$ ). Although some $\mathrm{TH}^{+}$neurons did not express ChR2-EYFP, 1516/1517 ChR2-EYFP ${ }^{+}$cells

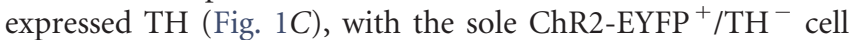
dorsal to the medial VTA. Therefore, within the ventral midbrain dopamine cell groups, all ChR2-EYFP ${ }^{+}$cells were $\mathrm{TH}^{+}$dopamine neurons, arguing against the contribution of VTA glutamate-only neurons (Hnasko et al., 2012).

To determine the efficacy of ChR2-EYFP expression in dopamine neurons, we counted cells in the medial and lateral portions of the VTA and the SNc (Fig. 2A). The overall transduction efficacy, measured as the percentage of $\mathrm{TH}^{+}$cells that were ChR2EYFP $^{+}$, was $82 \pm 3 \%$ in the VTA $\left(1180 / 1450 \mathrm{TH}^{+}\right.$cells counted $)$ and $63 \pm 6 \%$ in the $\mathrm{SNc}\left(336 / 539 \mathrm{TH}^{+}\right.$cells counted $)$. Along the anterior-posterior axis, transduction efficacy did not change significantly in either the VTA or the SNc (Fig. 2B1; Friedman's test; VTA: $\chi^{2}=11.00$, not significant (NS); SNc: $\chi^{2}=1.00$, NS). Transduced cells were found up to $740 \mu \mathrm{m}$ from the injection site and included dopamine neurons in the rostral linear nucleus and the central linear nucleus, making up the medial VTA (Phillipson, 1979; Fig. 1C2,C3). Along the medial-lateral axis, transduction efficacy decreased significantly $\left(\chi^{2}=10.2, p=0.017\right.$; Fig. $2 B 2$ ), with the lateral SNc showing the lowest values. Because ventral midbrain dopamine neurons expressing VGLUT2 are found mainly in the medial VTA (Kawano et al., 2006; Yamaguchi et al., 2011; Taylor et al., 2014; Yamaguchi et al., 2015), our viral injections targeted most ventral midbrain dopamine neurons expressing VGLUT2, and thus those with excitatory actions.

\section{Recording in forebrain dopaminergic projection regions}

The expression of ChR2-EYFP in dopamine neurons enabled wide-field photostimulation of their terminals impinging on recorded neurons. We selected the major projection areas of ventral midbrain dopamine neurons based on previous anatomical studies (Swanson, 1982; Björklund and Dunnett, 2007; Yetnikoff et al., 2014) and recorded glutamatergic EPSCs from 10 putative principal neurons in regions with ChR2-EYFP ${ }^{+}$axons. We pharmacologically isolated AMPA/kainate EPSCs with a mixture of $\mathrm{GABA}_{\mathrm{A}}, \mathrm{GABA}_{\mathrm{B}}, \mathrm{D} 1, \mathrm{D} 2$ dopamine, and muscarinic receptor antagonists and cells were clamped at $-75 \mathrm{mV}$ to maintain the $\mathrm{Mg}^{2+}$ blockade of NMDA receptor channels and prevent their activation. In all regions, CNQX completely blocked EPSCs, confirming that measured EPSCs were AMPA/kainate-receptor mediated and that any NMDA-receptor-mediated component was negligible. Dopamine neuron glutamatergic connections were deemed significant when EPSC peak amplitude exceeded a detec- 
A

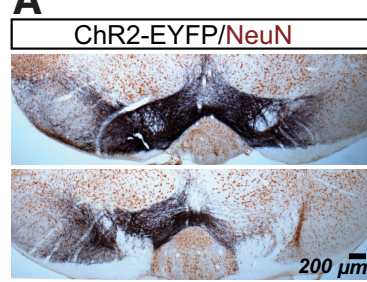

C1

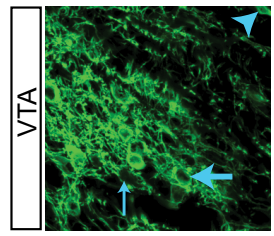

C3

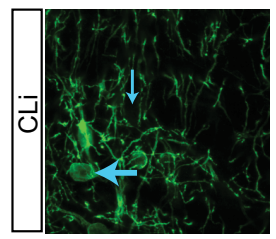

B
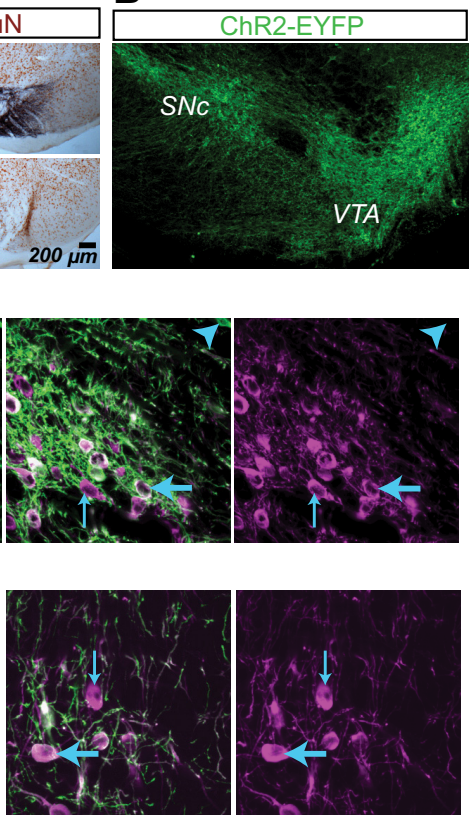
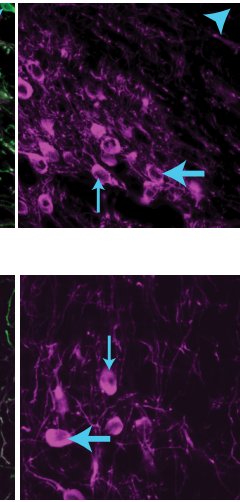
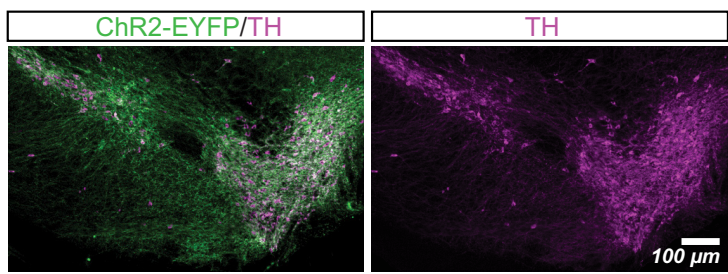

C2
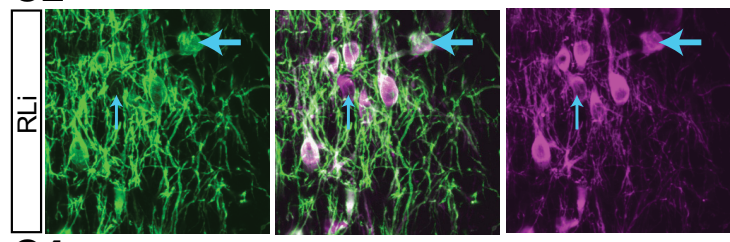

C4
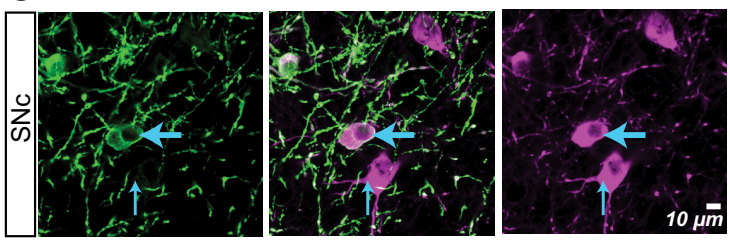

Figure 1. ChR2-EYFP expression in ventral midbrain dopamine neurons in DAT IREScre mice after AAV-DI0-ChR2-EYFP transduction. $A$, Immunoperoxidase staining showing the spread of ChR2-EYFP (black) expression in the ventral midbrain with neurons visualized with NeuN (brown). With bilateral injections, ChR2-EYFP spread to both VTA and the SN in most cases (top), whereas in a minority, ChR2-EYFP spread bilaterally to the VTA but only unilaterally to the SN (bottom). B, Confocal mosaic z-projected images of the ventral midbrain showing ChR2-EYFP (green, left) and TH immunoreactivity (magenta, right). Merged image (center) shows complete overlap. C, High-power z-projected images confirming ChR2-EYFP expression in TH ${ }^{+}$neurons in the VTA (C1), rostral linear nucleus (RLi; (2), central linear nucleus (CLi; (3), and SNc (C4). The blue arrowhead in $\mathrm{C} 1$ indicates the sole ChR2-EYFP ${ }^{+} / \mathrm{TH}^{-}$cell found in this study. Thin blue arrows indicate ChR2-EYFP ${ }^{-} / \mathrm{TH}^{+}$cells and thick blue arrows indicate ChR2-EYFP ${ }^{+} / \mathrm{TH}^{+}$cells.

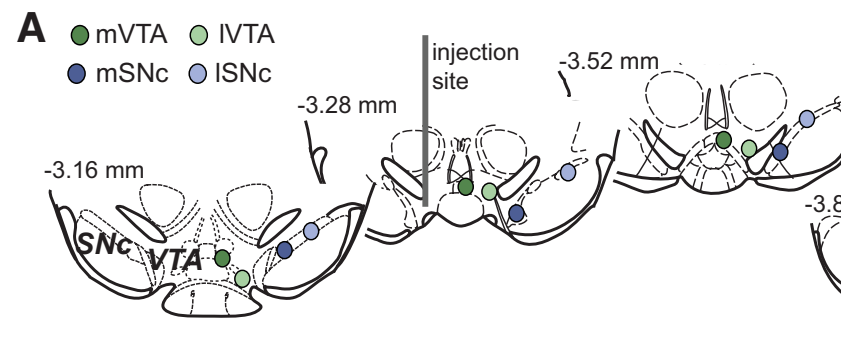

B1

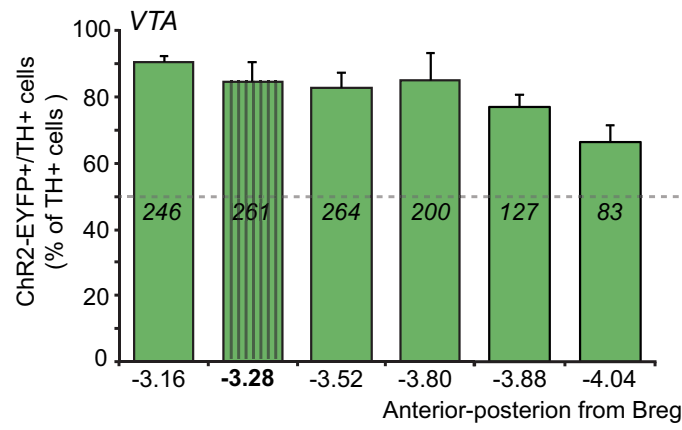

SNc

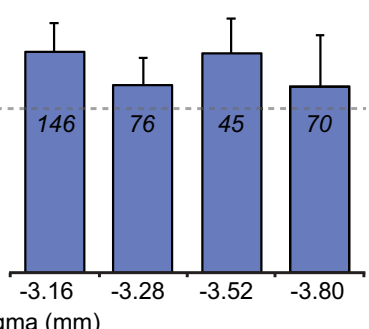

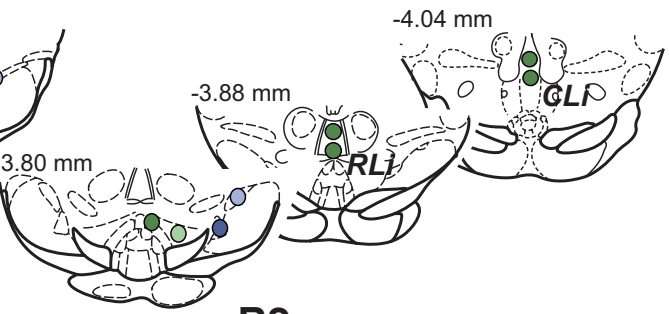

B2

Figure 2. Distribution of ChR2-EYFP transduced dopamine neurons in the VTA and SNc. A, Schematics, adapted from Paxinos and Franklin (2001) here and in subsequent figures, show the locations where confocal images were acquired for cell counts in the medial (mVTA; dark green circles), lateral VTA (IVTA; light green circles), medial SN (mSN; dark blue circles), and lateral SN (ISN; light blue circles). The dark gray bar in the slice at $-3.28 \mathrm{~mm}$ from bregma shows the viral vector injection site in the IVTA. $\boldsymbol{B}$, Transduction efficacy is expressed as the percentage of ChR2-EYFP ${ }^{+}$ cells among $\mathrm{TH}^{+}$cells. Numbers within the bars correspond to the total number of cells counted at each location ( $n=4$ mice). Gray dashed lines indicate $50 \%$ efficacy. B1, Along the anterior-posterior axis in the VTA (green bars) and SNc (blue bars), high transduction efficacy was seen in the VTA and lower in the SNc at all anterior-posterior levels. B2, Transduction efficacy decreased from medial to lateral ventral midbrain. The striped bars indicate the location of the injection site.

tion threshold set to the preceding mean baseline amplitude plus 2 SDs. For each region with connections, we report the detection threshold, the incidence of connections, and the strength of the connections, calculated as the mean EPSC amplitude for all cells with a connection. For regions without connections, we report the detection threshold and the peak amplitude after photostimulation, calculated as the mean of the maximum amplitude in the $50 \mathrm{~ms}$ after photostimulation. 

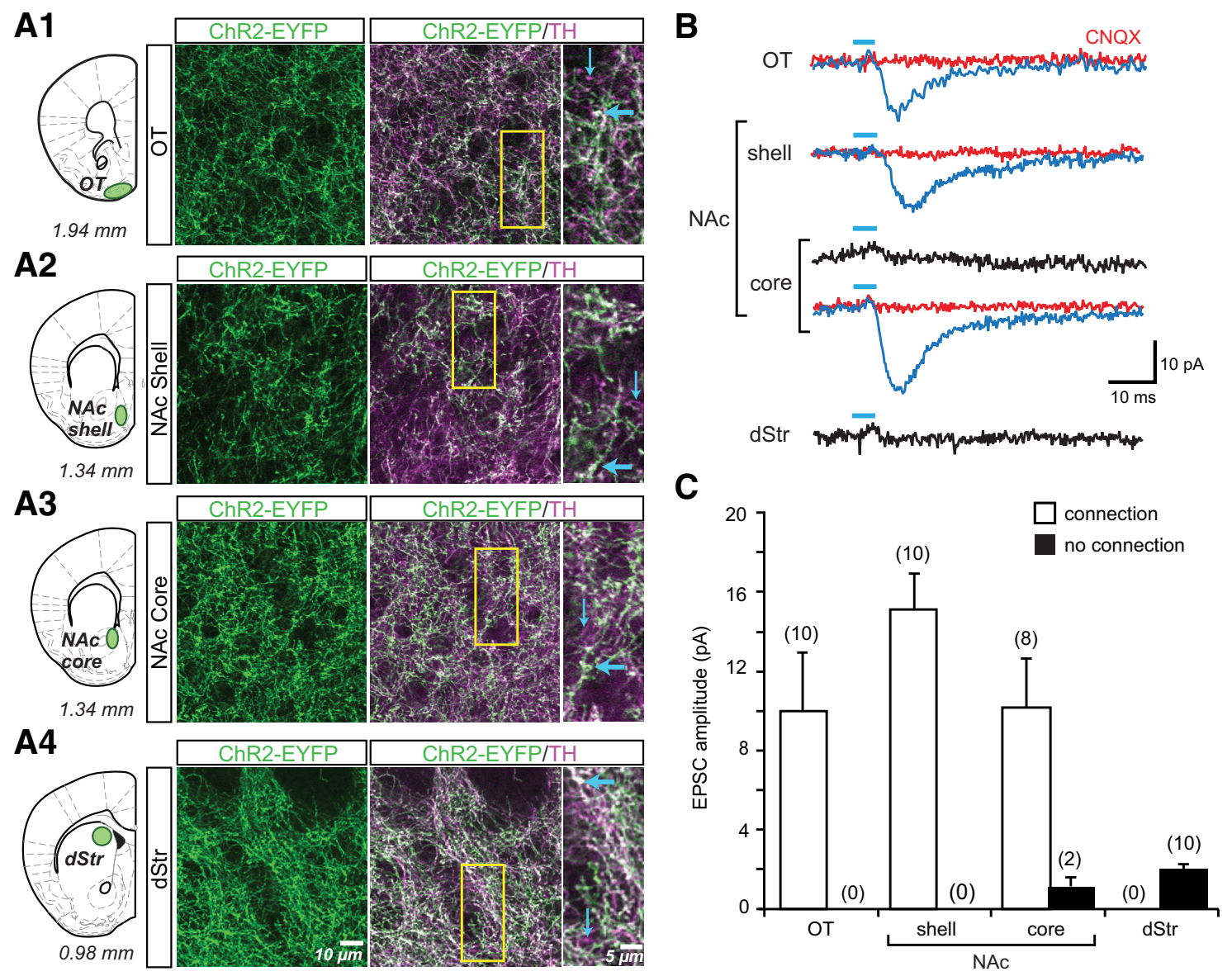

Figure 3. ChR2-EYFP expression in dopamine neuron axons and photostimulated glutamatergic responses in the striatum. $A$, Confocal immunofluorescence images of ChR2-EYFP ${ }^{+}$and TH ${ }^{+}$ axons in the 0T (A1), NAc shell (A2), NAc core (A3), and dStr (A4) are shown. Schematics (right) show the coronal slices, with distance from bregma indicated below each section, that were used for immunostaining and in vitro EPSC recordings; sites of image acquisition and recording are outlined in green. The three columns of images show ChR2-EYFP ${ }^{+}$axons (green), the merge of

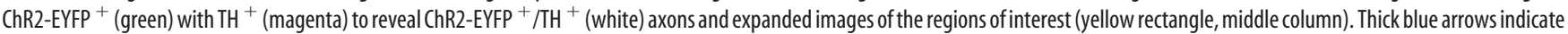
ChR2-EYFP ${ }^{+} / \mathrm{TH}^{+}$axons; thin blue arrows indicate ChR2-EYFP ${ }^{-} / \mathrm{TH}^{+}$axons. No ChR2-EYFP ${ }^{+} / \mathrm{TH}^{-}$axons were seen in the striatum. $\boldsymbol{B}$, Recordings were made from SPNs in the four sites in the striatum. EPSCs shown are the average of 10 consecutive traces. Traces with significant light-evoked responses are shown in blue; those without responses are shown in black. Blue bars above traces indicate photostimulation (5 ms pulses, at $0.1 \mathrm{~Hz}$ ). CNQX (40 $\mu \mathrm{m}$ ) completely blocked light-evoked EPSCs (red traces). C, Summary of the amplitudes of recorded light-evoked EPSCs in different regions of the striatum. The graph shows the average amplitudes in SPNs with EPSCS (connection; white bars) and without (no connection; black bars). The number of cells recorded is shown in parentheses.

Dopamine neuron glutamatergic connections in the striatum ChR2-EYFP-labeled axons were the densest in the striatum and coexpressed TH-ir, defining their dopaminergic nature (Fig. $3 A$ ). ChR2-EYFP ${ }^{-} / \mathrm{TH}^{+}$axonal processes were rarely seen, confirming high transduction efficacy and indicating that ChR2-EYFP was expressed throughout the axonal tree of transduced neurons (Fig. 3A, insets). The medial dStr consistently showed higher levels of ChR2-EYFP expression than the lateral dStr (data not shown), reflecting the lower transduction in the lateral SN (Fig. $2 B 2$ ). For this reason, all dStr axonal density and recording measures were made in the medial dStr (Fig. 3A4). The density of ChR2-YFP fibers was measured as the average number of pixels in a $1048 \times 1048$ pixel frame. The numbers of ChR2-EYFP ${ }^{+}$ axonal pixels were as follows: $272,242 \pm 54,412$ for the OT; 262, $484 \pm 35,361$ for the NAc shell; $242,173 \pm 42,962$ for the NAc core; and 235,928 $\pm 15,910$ for the medial dStr. Within recording areas, the distribution of terminals was relatively homogeneous. There were no significant differences among subdomains (oneway ANOVA; $F_{(3,10)}=0.23$; NS).

In the striatum, we recorded photostimulated responses from putative spiny projection neurons (SPNs) in the vStr, including the OT, the NAc medial shell and core, and in the medial dStr (Fig. $3 B, C$ ). The resulting EPSCs were completely blocked by CNQX (40 $\mu \mathrm{M}$; red traces in Fig. $3 B$ ), confirming glutamatergic mediation. In the NAc shell and the OT, dopamine neurons made glutamatergic connections to SPNs with similar incidence and strength (NAc shell: detection threshold: $3.56 \pm 0.36 \mathrm{pA}$; incidence of connections: 10/10 cells; connection strength: $15.09 \pm$ 1.96 pA; OT: detection threshold: $4.12 \pm 0.94 \mathrm{pA}$; incidence of connections: 10/10 cells; connection strength: $9.97 \pm 3.11 \mathrm{pA}$; Fig. $3 B, C)$. In the NAc core, the number of connected cells decreased, whereas the average strength was similar to that recorded in the OT (detection threshold: $3.52 \pm 0.42 \mathrm{pA}$; incidence of connections: $8 / 10$ cells; connection strength: $10.19 \pm 2.64 \mathrm{pA}$; Fig. $3 B, C$ ). No connections were seen in the dStr (detection threshold: $2.46 \pm 0.38 \mathrm{pA}$; peak amplitude postphotostimulation: $2.02 \pm 0.24 \mathrm{pA}$ ). Therefore, the distribution of dopamine neuron glutamatergic connections in the striatum was more prominent in the ventromedial regions and weaker in more dorsolateral regions, consistent with the medial distribution of VGLUT2 in ventral midbrain dopamine neurons. 
A

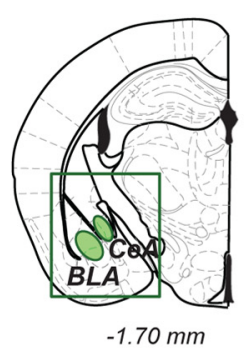

B1

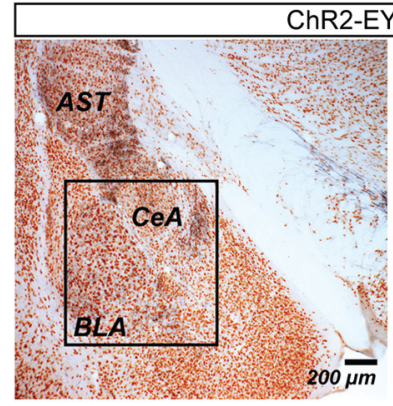

B2

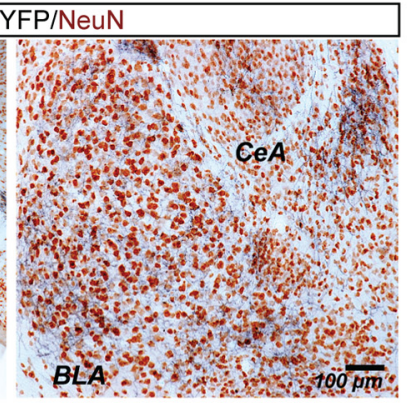

C

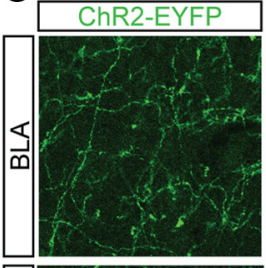

ChR2-EYFP/T

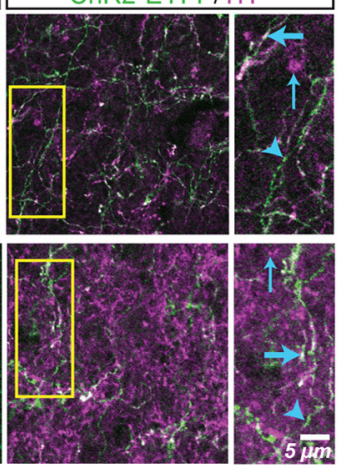

D

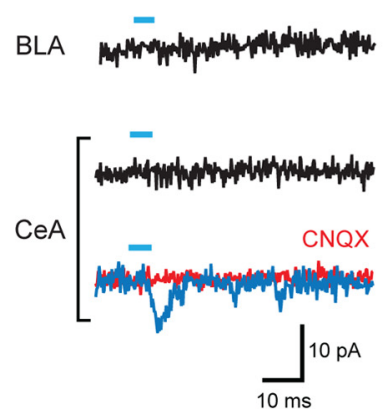

B3

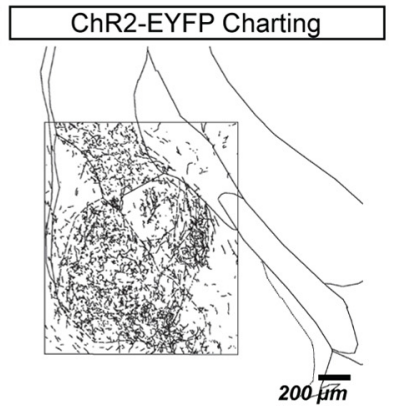

E

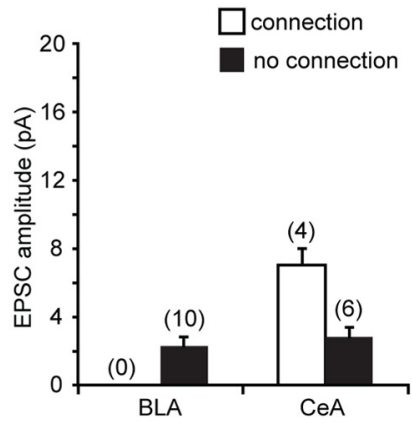

Figure 4. ChR2-EYFP expression in dopamine neuron axons and photostimulated glutamatergic responses in the amygdala. $\boldsymbol{A}$, Schematic showing the amygdala brain slice used for immunostaining and in vitro EPSC recordings; sites of image acquisition and recording are outlined in green. $\boldsymbol{B}$, Two-color immunoperoxidase staining of ChR2-EYFP ${ }^{+}$axons (black) and the neuronal marker NeuN (brown). The region of interest containing the amygdala (B1) is expanded on the right (B2). Charting of ChR2-EYFP ${ }^{+}$axons in the area shown in $\boldsymbol{B} 2$ reveals similar densities of dopamine neuron axons in BLA and CeA (B3). C, Confocal immunofluorescence images of ChR2-EYFP ${ }^{+}$and $\mathrm{TH}^{+}$axons in the BLA and CeA. The three columns of images show ChR2-EYFP ${ }^{+}$axons (green), the merge of ChR2-EYFP ${ }^{+}$(green) with $\mathrm{TH}^{+}$(magenta) to reveal ChR2-EYFP ${ }^{+} / \mathrm{TH}^{+}$(white) axons and expanded images of the regions of interest (yellow rectangle, middle column). Thick blue arrows indicate ChR2-EYFP ${ }^{+} / \mathrm{TH}^{+}$axons; thin blue arrows indicate ChR2-EYFP ${ }^{-} / \mathrm{TH}^{+}$axons; arrowheads indicate ChR2-EYFP ${ }^{+} / \mathrm{TH}^{-}$axons. D, Recordings were made from principal neurons in the BLA and CeA. EPSCs shown are the average of 10 consecutive traces. Traces with significant light-evoked responses are shown in blue; those without responses are shown in black. Blue bars above traces indicate photostimulation ( $5 \mathrm{~ms}$ pulses, at $0.1 \mathrm{~Hz}$ ). CNQX (40 $\mu \mathrm{m}$ ) completely blocked light-evoked EPSCs (red trace). $\boldsymbol{E}$, Summary of the amplitudes of recorded light-evoked EPSCs in the two amygdala nuclei. The graph shows the average amplitudes in cells with EPSCs (connection; white bars) and without (no connection; black bars). The number of cells recorded is shown in parentheses. No BLA cells showed light-evoked EPSCS. AST, Amygdalo-striatal transition area.

\section{Dopamine neuron glutamatergic connections in the amygdala} Charting of ChR2-EYFP ${ }^{+}$dopamine neuron axons in the amygdala (Fig. $4 A, B$ ) revealed that the axons were densely and homogeneously distributed in the basolateral amygdala (BLA). In the central nucleus (CeA), ChR2-EYFP ${ }^{+}$dopamine neuron axons appeared most dense in the medial subnucleus, where the density of axons approximated that of the BLA (Fig. 4B). Overall, the number of ChR2-EYFP pixels did not differ between the BLA and the medial CeA: $86,844 \pm 24,545$ pixels in the BLA and $80,427 \pm 19,664$ pixels in the CeA (one-way ANOVA; $F_{(1,6)}=$ 0.06 ; NS). Double immunofluorescence showed that ChR2EYFP $^{+}$axons coexpressed TH (Fig. 4C) and were intermingled with singly labeled $\mathrm{TH}^{+}$or ChR2-EYFP ${ }^{+}$axons. Because TH also labels noradrenergic axons in the amygdala (Freedman and Cassell, 1994), the efficacy of ChR2-EYFP expression in dopamine neuron axons is likely an underestimate. In addition to the CeA and BLA, dense ChR2-EYFP ${ }^{+}$dopamine neuron axons were seen in the amygdalostriatal transition zone.

We recorded from the smaller neurons in the CeA, which are putative GABAergic projection neurons, and large neurons in the rostral magnocellular portion of the BLA, which are putative glutamatergic projection neurons. Photostimulation of dopaminergic terminals only elicited significant EPSCs in the CeA (detection threshold: $5.18 \pm 0.44 \mathrm{pA}$; incidence of connections: $4 / 10$ cells; connection strength: $7.17 \pm 1.24 \mathrm{pA}$ ), but not in the BLA (detection threshold: $2.26 \pm 0.56 \mathrm{pA}$; peak amplitude after photostimulation: $2.07 \pm 0.58 \mathrm{pA}$ ) (Fig. $4 D, E$ ). Therefore, although dopamine neurons project to both amygdala nuclei, they only made glutamatergic connections in the CeA.

\section{Dopamine neuron glutamatergic connections in the hippocampal formation}

In the hippocampal formation (Fig. $5 A$ ), dense aggregations of

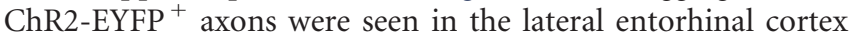
(ERC), in a distribution similar to previously reported dopamine islands (Fallon et al., 1978; Bentivoglio and Morellis, 2005). In the gray matter matrix of the ERC surrounding the dopamine islands, the density of ChR2-EYFP ${ }^{+}$axons was markedly lower than in the axon clusters in the islands (ERC island pixels: 52,593 \pm 10,843; ERC matrix pixels: 19,321 \pm 2853; Fig. 5B1,B2). Very sparse ChR2-EYFP ${ }^{+}$axons were seen in the hippocampus, with only a few ChR2-EYFP ${ }^{+}$axons in the dentate gyrus (DG), ventral subiculum (VS) and CA1 (Fig. 5B3). In accordance with these observations, measured ChR2-EYFP pixel density in the CA1 was very low $(1752 \pm 298)$. The differences in axon density between subregions of the hippocampal formation were significant $\left(F_{(2,7)}=31.1 ; p<0.001\right)$, with post hoc tests revealing higher densities in ERC island compared with ERC matrix $(p=0.006)$ and CA1 $(p=0.0003)$. There was a trend toward a difference in density between ERC matrix and CA1 $(p=0.081)$. In the CA1, ChR2-EYFP ${ }^{+} / \mathrm{TH}^{+}$axons were rare; Figure $5 C$ (top) shows one of the few axons found in the stratum oriens division of CA1. We 
A

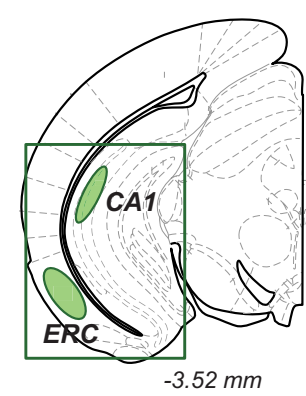

C
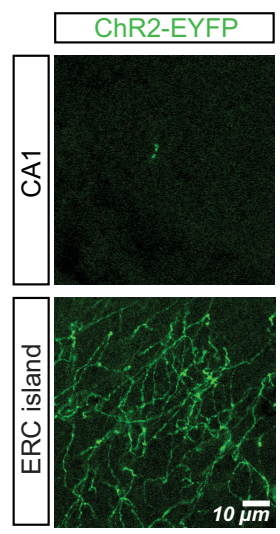

B1

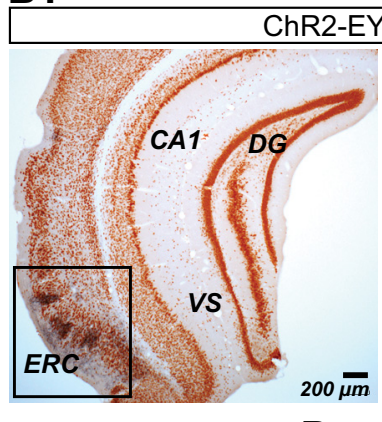

D
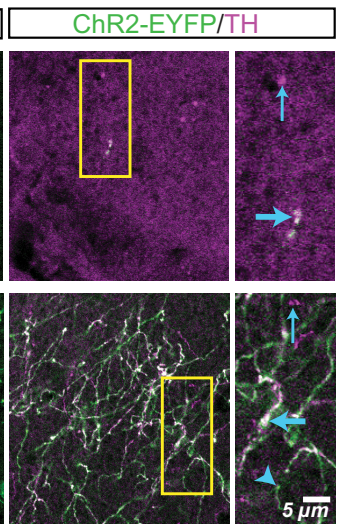

B2

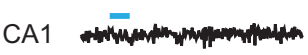

matrix
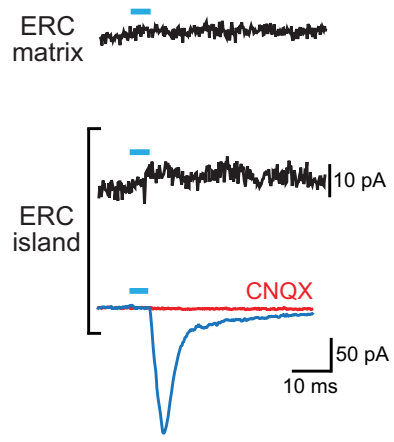

B3

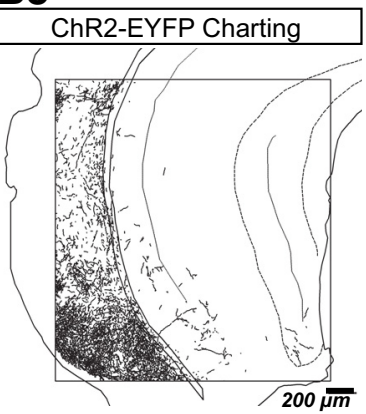

E

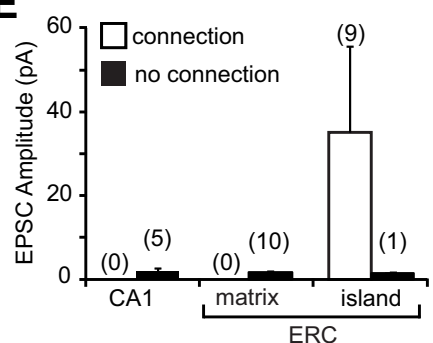

F1

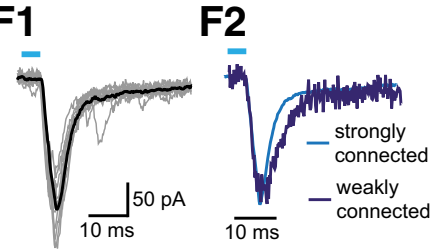

Figure 5. ChR2-EYFP expression in dopamine neuron axons and glutamatergic responses in the hippocampal formation. $\boldsymbol{A}$, Schematic shows the hippocampal formation brain slice used for immunostaining and in vitro EPSC recordings; sites of image acquisition and recording are outlined in green. $\boldsymbol{B}$, Two-color immunoperoxidase staining of ChR2-EYFP ${ }^{+}$axons (black) and the neuronal marker NeuN (brown). The region of interest centered on dopamine islands in the ERC (B1) is expanded to the right (B2). Charting of ChR2-EYFP ${ }^{+}$axons revealed densely aggregated dopamine neuron axons in the ERC (B3) and sparse innervation in the VS, DG, and CA1 subregions. C, Confocal immunofluorescence images of ChR2-EYFP ${ }^{+}$and TH ${ }^{+}$axons in the hippocampal formation. The three columns of images show ChR2-EYFP ${ }^{+}$axons (green), the merge ofChR2-EYFP ${ }^{+}$(green) with $\mathrm{TH}^{+}$(magenta) to reveal ChR2-EYFP ${ }^{+} / \mathrm{TH}^{+}{ }^{+}$(white) axons, and expanded images of the regions of interest (yellow rectangles, middle column). Thick blue arrows indicate ChR2-EYFP ${ }^{+} / \mathrm{TH}^{+}$axons; thin blue arrows indicate ChR2-EYFP ${ }^{-} / \mathrm{TH}^{+}{ }^{+}$axons; $^{-}$arrowheads indicate ChR2-EYFP $^{+} / \mathrm{TH}^{-}$ axons. In the CA1 (top images), ChR2-EYFP ${ }^{+} / \mathrm{TH}^{+}$axons were very rare. In contrast, in the ERC dopamine islands (bottom images), ChR2-EYFP ${ }^{+}$axons were relatively abundant. D, Recordings from principal neurons in the hippocampal subregions. EPSCs shown are the average of 10 consecutive traces. The trace with a significant light-evoked response is shown in blue; those without responses are shown in black. Blue bars above traces indicate photostimulation ( 5 ms pulses, at $0.1 \mathrm{~Hz}$ ). CNQX (40 $\mu \mathrm{m}$ ) completely blocked the light-evoked EPSC (red trace). $\boldsymbol{E}$, Summary of the amplitudes of recorded light-evoked EPSCs in the hippocampal subregions shows the average amplitudes in cells with EPSCs (connection; white bars) and without (no connection; black bars). The number of cells recorded is shown in parentheses. Only ERC island cells showed light-evoked EPSCs. F1, Individual EPSCs for the strongest ERC connection (10 traces are shown) reliably and tightly superimposed on the averaged EPSC. F2, Two superimposed traces normalized for peak amplitude, one from a strongly connected cell (light blue; EPSC amplitude of $197 \mathrm{pA}$ ) and another from a weakly connected cell (dark blue; EPSC amplitude $17 \mathrm{pA}$ ) show identical rise times, confirming that the responses were monosynaptic.

saw ChR2-EYFP ${ }^{-} / \mathrm{TH}^{+}$axons in CA1, which could be either axons of dopamine neurons that do not express DAT (the promoter used to drive ChR2-EYFP expression) or noradrenergic axons. The aggregation of ChR2-EYFP ${ }^{+}$axons in the ERC were $\mathrm{TH}^{+}$(Fig. $5 \mathrm{C}$, bottom). Therefore, in the hippocampal formation, dopamine neurons predominantly project to the ERC, in agreement with previous anatomical studies in the rat (Swanson, 1982).

Within the hippocampal formation, recordings were made from pyramidal neurons in slices encompassing CA1 and ERC. In contrast to bright ChR2-EYFP fluorescence seen in the ERC, ChR2-EYFP fluorescence in the hippocampus was very dim and fluorescent axons extremely rare. Consistent with this, we found no significant EPSCs in CA1 pyramidal cells (detection threshold: $3.11 \pm 0.70 \mathrm{pA}$; peak amplitude after photostimulation: $1.96 \pm$ 0.84 pA; Fig. $5 D, E$ ). In ERC, we observed strong glutamatergic connections in islands (detection threshold: $4.09 \pm 0.50 \mathrm{pA}$; incidence of connections: $9 / 10$ cells; connection strength: $35.19 \pm$ $21.88 \mathrm{pA}$ ), but not in the surrounding matrix (detection threshold: $1.64 \pm 0.34 \mathrm{pA}$; peak amplitude postphotostimulation: $1.76 \pm 0.60 \mathrm{pA}$; Fig. $5 D, E)$. The dopamine neuron glutamatergic connections in ERC islands were the strongest we found but also the most variable, ranging from 4 to $192 \mathrm{pA}$. This variability was not due to polysynaptic recruitment of other glutamatergic neurons because connections showed short and relatively fixed latencies ranging from 4.3 to $8.9 \mathrm{~ms}$ (measured from the onset of illumination). Examining the strongest ERC connection, which would be the most likely to include a polysynaptic contribution, the individual EPSCs nonetheless reliably and tightly superimposed on the averaged response (Fig. 5F1). Superposition of a scaled-up weaker EPSC on a stronger EPSC revealed further that responses were monophasic with matching time course (Fig. $5 F 2$ ). Therefore, in the hippocampal formation, dopamine neurons make monosynaptic glutamatergic connections to pyramidal neurons in ERC islands.

\section{Dopamine neuron glutamatergic connections in the} anterior cortices

There was a sparse ChR2-EYFP ${ }^{+}$innervation in anterior cortical areas (Fig. $6 A-D$ ). In the prefrontal cortex (PFC) most $\mathrm{ChR}$-EYFP ${ }^{+}$axons were in layers $\mathrm{V}$ and VI, whereas in the cingulate cortex (CIN), most ChR2-EYFP ${ }^{+}$axons were in layers II-III (Fig. 6B,D), consistent with the laminar distribution 
A

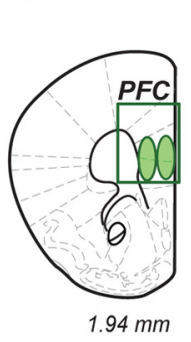

B1

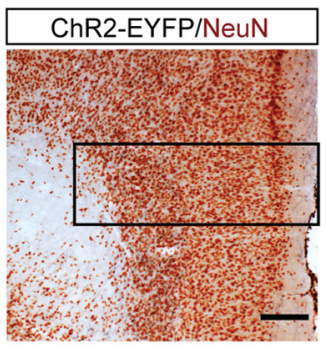

B2

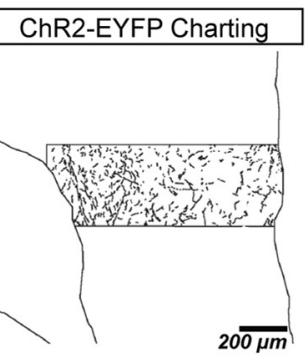

C

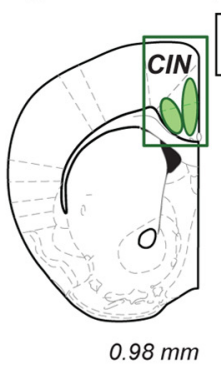

D1

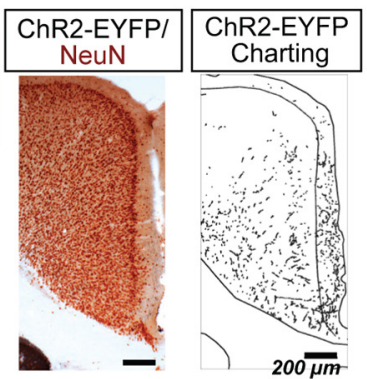

E
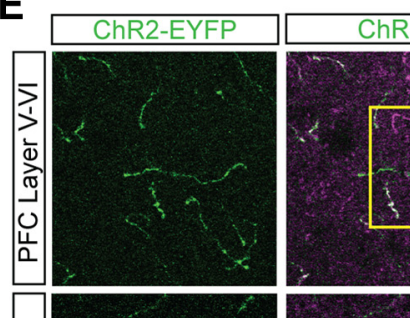

R2-EYFP/T
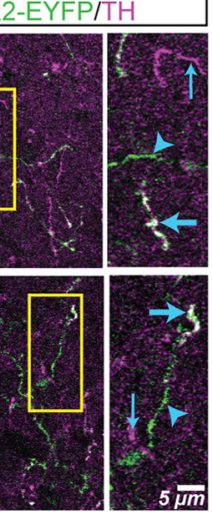

$\mathbf{F}$

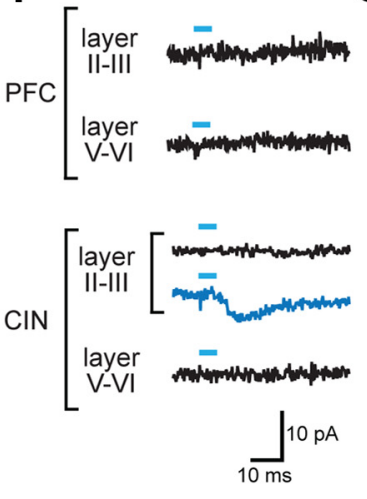

G

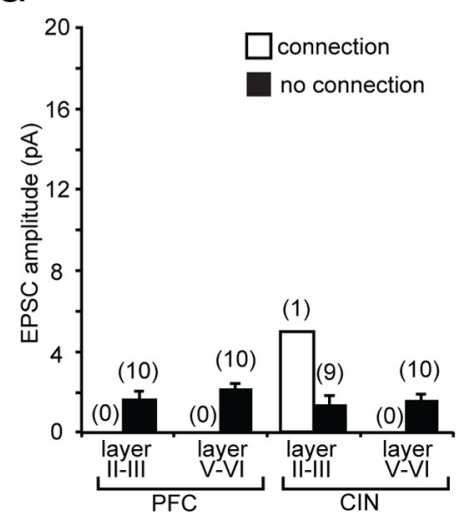

Figure 6. ChR2-EYFP expression in dopamine axons and glutamatergic responses in the anterior cortices. $A$, Schematic showing the coronal brain slice through the PFC used for immunostaining and in vitro EPSC recordings; sites of image acquisition and recording in layers II-III and V-VI are outlined in green. $\boldsymbol{B}$, Two-color immunoperoxidase staining reveals ChR2-EYFP ${ }^{+}$axons (black) and the neuronal marker NeuN (brown). The region of interest traversing the cortical thickness (B1) is shown to the right (B2) with charting of ChR2-EYFP ${ }^{+}$axons. C, Schematic showing the coronal brain slice through the CIN; sites of image acquisition and recording in layers III-III and V-VI are outlined in green. $\boldsymbol{D}$, Two-color immunoperoxidase staining reveals ChR2-EYFP ${ }^{+}$axons (black) and the neuronal marker NeuN (brown). The region of interest encompassing the CIN regions (D1) is shown to the right (D2) with charting of ChR2-EYFP ${ }^{+}$axons. The charting in the PFC and CIN reveals

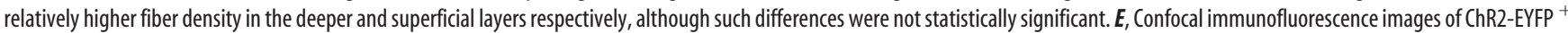
and $\mathrm{TH}^{+}$axons in the two cortical regions. The three columns of images show ChR2-EYFP ${ }^{+}$axons (green), the merge of ChR2-EYFP ${ }^{+}$(green) with TH ${ }^{+}$(magenta) to reveal ChR2-EYFP ${ }^{+} / \mathrm{TH}^{+}$ (white) axons, and expanded images of the regions of interest (yellow rectangle, middle column). Thick blue arrows indicate ChR2-EYFP ${ }^{+} / \mathrm{TH}^{+}$axons; thin blue arrows indicate ChR2-EYFP ${ }^{-} / \mathrm{TH}^{+}$

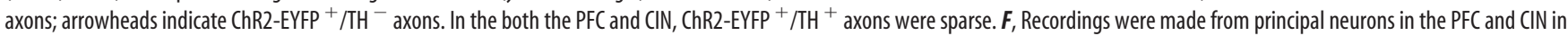
layers II-III and layers V-VI. EPSCs shown are the average of 10 consecutive traces. The trace in blue shows a significant light-evoked response; those in black show no responses. Blue bars above traces indicate photostimulation (5 ms pulses, at $0.1 \mathrm{~Hz}$ ). Only one cell in layers II-III of the CIN showed a significant EPSC (blue trace); all other cells showed no light-evoked EPSCs (black traces). $\mathbf{G}$, Summary of the amplitudes of recorded light-evoked EPSCs in the PFC and CIN shows the average amplitudes in cells with EPSCs (connection; white bars) and without (no connection; black bars). The number of cells recorded is shown in parentheses. Only one cell showed an excitatory connection.

of the dopaminergic innervation of the rat cortex (Descarries et al., 1987; Berger et al., 1991). The quantification of ChR2EYFP pixels revealed a similar trend. In the PCF, we counted $7666 \pm 3308$ pixels in layers II-III, with double the number of pixels in layers V-VI $(15,385 \pm 4867)$. In the CIN, we counted $23,198 \pm 12,588$ pixels in layers II-III and approximately half the number in layers V-VI (10,992 \pm 3284 pixels $)$. However, differences in the density across layers were not statistically significant (one-way ANOVA; $F_{(3,10)}=1.514$; NS). Highpower photomicrographs revealed a low density of ChR2$\mathrm{EYFP}^{+} / \mathrm{TH}^{+}$axons intermingled with singly labeled $\mathrm{TH}^{+}$and ChR2-EYFP $^{+}$axons (Fig. 6E).

Recording from pyramidal neurons in the anterior cortices revealed a significant synaptic response in only 1 of 10 recorded layer II-III CIN pyramidal cell (detection threshold: $3.48 \pm 0.68$ pA; incidence of connections: $1 / 10$ cells; connection strength: 5.0 pA; Fig. $6 F, G)$. No connections were seen in other cortical areas (CIN layers V-VI: detection threshold: $2.44 \pm 0.55 \mathrm{pA}$; peak amplitude after photostimulation: $1.76 \pm 0.54 \mathrm{pA}$; PFC layers II-III: detection threshold: $2.30 \pm 0.52 \mathrm{pA}$; peak amplitude after photostimulation: $1.66 \pm 0.39 \mathrm{pA}$; PFC layers V-VI: detection threshold: $2.22 \pm 0.83 \mathrm{pA}$; peak amplitude after photostimula- tion: $2.21 \pm 0.35 \mathrm{pA}$ ). Therefore, dopamine neuron glutamatergic connections in the anterior cortices are very weak.

\section{Regional comparison of dopamine neuron glutamatergic connections and the density of ChR2-EYFP ${ }^{+}$axons}

We systematically compared the incidence and strength glutamatergic connections across forebrain regions (Fig. 7A). We found the highest incidence of connections (10/10 cells) in the NAc and OT, followed by the dopamine islands of the ERC ( $9 / 10$ cells), then the NAc core (8/10), the CeA (4/10), and the CIN $(1 / 10)$. The strongest glutamatergic connections were found in the ERC $(35.19 \pm 21.88 \mathrm{pA})$, followed by the NAc shell $(15.09 \pm 1.96 \mathrm{pA})$ and core $(10.19 \pm 2.64 \mathrm{pA})$, OT $(9.97 \pm 3.11 \mathrm{pA})$, CeA (7.17 \pm $1.24 \mathrm{pA})$, and the CIN (5.0 pA). Although the overall strength of the responses varied, other synaptic parameters did not differ significantly across regions. Average EPSC latency was $\sim 6 \mathrm{~ms}$ (Fig. 7B1; OT: $6.40 \pm 0.96 \mathrm{~ms}$; NAc shell: $5.54 \pm 0.36 \mathrm{~ms}$; NAc core: $5.38 \pm 0.89 \mathrm{~ms}$; CeA: $5.35 \pm 1.68 \mathrm{~ms}$; ERC: $6.00 \pm 0.63$; and CIN: 6.47). Latencies did not differ significantly between regions (one-way ANOVA; $F_{(4,35)}=0.349$; NS). EPSC rising phases were monophasic, with rise times of $\sim 3 \mathrm{~ms}$ (Fig. 7 B2; OT: $3.21 \pm 0.46$ ms; NAc shell: $3.09 \pm 0.21 \mathrm{~ms}$; NAc core: $2.75 \pm 0.37 \mathrm{~ms}$; CeA: 

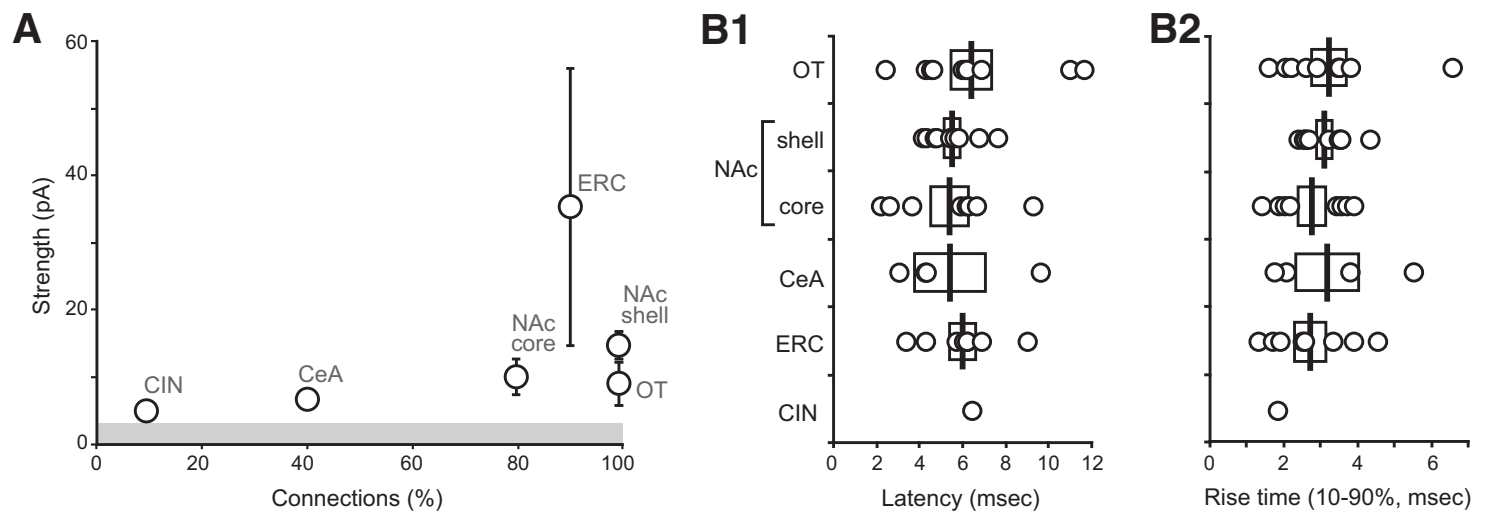

Figure 7. Comparison of the strength and timing characteristics of dopamine neuron glutamatergic EPSCS. A, Scatter plot showing the relationship between the incidence of connections (ratio of cells with connection of 10 recorded cells) and the connection strength (average amplitude of EPS(s in cells with connections) for each projection area. The gray bar indicates the average detection threshold $(3.99 \pm 0.29 \mathrm{pA})$ for connections in all recorded forebrain areas with connections. $\boldsymbol{B}$, Distribution of latencies of glutamatergic responses (B1) and rise times (B2) for the regions with connections. Latency was short and both latency and rise time were tightly distributed, consistent with monosynaptic connectivity.

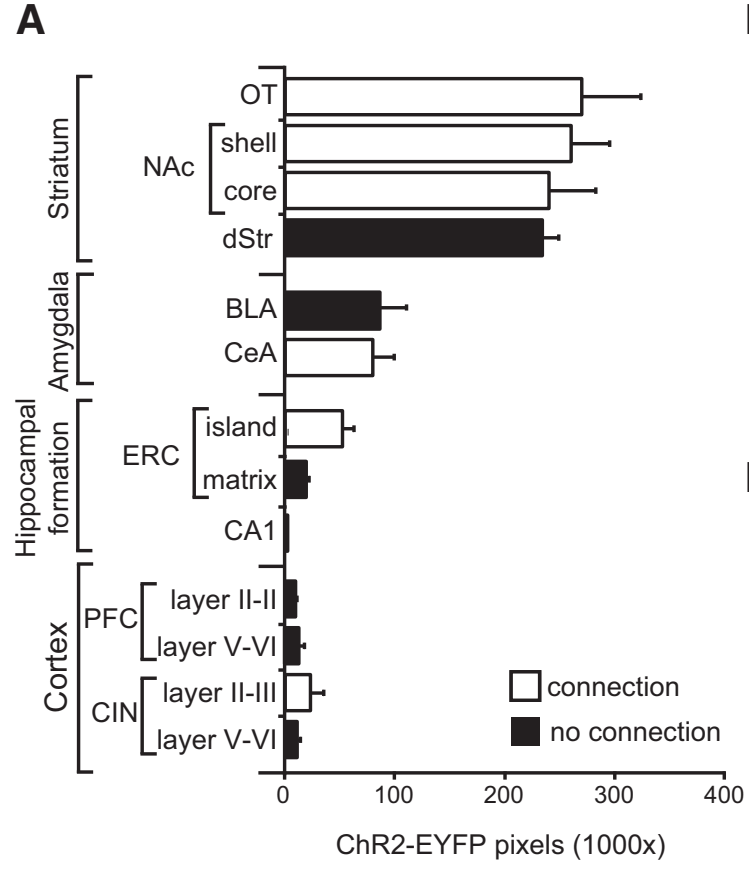

Figure 8. Regional differences in ChR2-EYFP axon density and glutamatergic connections. A, Comparison of the density of ChR2-EYFP ${ }^{+}$axons in the different forebrain regions expressed as the number of fluorescent pixels in the $1024 \times 1024$ frame $(1,048,576$ pixels). White bars indicate subregions where significant connections were found and black bars regions where no excitatory connections were found; $n=4$ mice. $\boldsymbol{B}$, Scatter plot showing the relationship between the incidence of connections and the density of ChR2-YFP ${ }^{+}$axons (B1) and the strength of connections and the density of ChR2-YFP ${ }^{+}$axons (B2). Pearson's correlation coefficients ( $r$ values) are shown for all regions with connections including and excluding the ERC.

axons in forebrain areas per se did not predict the presence of glutamatergic connections. This was evident in the striatum, where ChR2-EYFP ${ }^{+}$axons were dense in all subregions, but no glutamatergic connections were seen in the dStr. A striking discordance was also found in the amygdala nuclei, where both BLA and CeA showed similar ChR-EYFP ${ }^{+}$axonal densities, but glutamatergic synaptic connectivity was only found in the CeA. Comparing axonal density using a twoway ANOVA, with region (striatal complex, amygdala, hippocampal formation, and anterior cortices) and connectivity (with or without excitatory connections) as between-subject factors, revealed a significant main effect of region $\left(F_{(3,39)}=\right.$ $60.7 ; p<0.001)$, but not of connectivity $\left(F_{(1,39)}=0.56\right.$; NS), nor was there a significant interaction $\left(F_{(2,39)}=1.18\right.$; NS).

We then focused on regions with glutamatergic connections and investigated how the regional density of ChR2-EYFP ${ }^{+}$ axons correlated with the incidence and strength of glutamatergic connections (Fig. 8B). We compared these measures in all regions with connections and then after excluding ERC island connections because the ERC island connections were more than twice as strong as the other connections and their strength varied

$3.28 \pm 1.00 \mathrm{~ms}$; ERC: $2.72 \pm 0.43 \mathrm{~ms}$; and CIN:1.83). Rising times did not differ significantly between regions (one-way ANOVA; $F_{(4,35)}=0.379$; NS). These EPSC parameters matched with previous reports (Tecuapetla et al., 2010; Adrover et al., 2014; Chuhma et al., 2014; Wieland et al., 2014) and are consistent with monosynaptic connectivity.

We examined the relationship between the density of dopamine neuron ChR2-EYFP ${ }^{+}$axons and connectivity (Fig. 8A). The striatum showed the highest density of ChR2-EYFP ${ }^{+}$axons, followed by moderate density in the amygdala and ERC islands of the hippocampal formation and the lowest density in the ERC matrix, CA1, and PFC and CIN. The expression of ChR2-EYFP ${ }^{+}$ widely. We found that there was a strong positive correlation between density of ChR2-EYFP ${ }^{+}$axons and the incidence of connections (Pearson's $r=0.74$; Fig. $8 B 1$ ) that approached but did not reach statistical significance (regression analysis: $F_{(1,5)}=$ 4.837; $p=0.09$ ). Excluding the ERC connections, there was an almost perfect positive correlation between the density of ChR2EYFP $^{+}$axons and incidence of connections $\left(r=0.99 ; F_{(1,4)}=\right.$ $120.54 ; p=0.02$ ). A similar effect was found for the correlation between axonal density and connection strength, with no correlation including all connected regions $\left(r=-0.18 ; F_{(1,5)}=0.139\right.$; NS; Fig. 8B2). Excluding the ERC connections, there was a signif- 


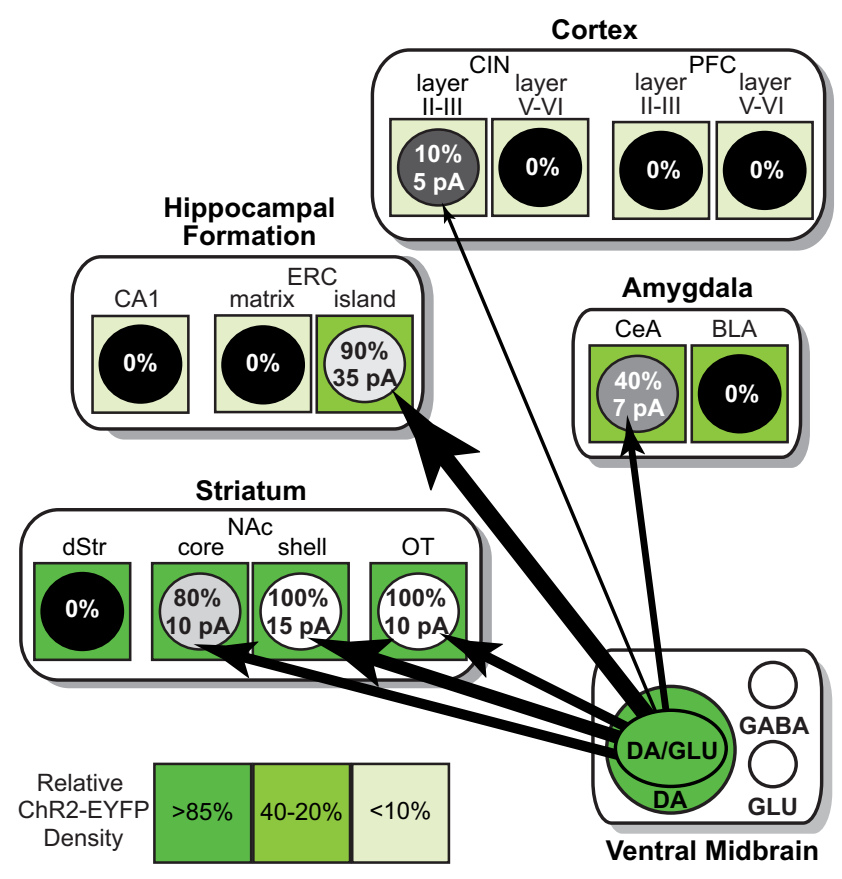

Figure 9. Dopamine neuron glutamatergic functional connectome in the forebrain. In the ventral midbrain, the large green circle represents dopamine neurons expressing ChR2-EYFP; the inner green ellipse (DA/GLU) represents the subpopulation of dopamine neurons that expresses ChR2-EYFP and coreleases glutamate. Within projection target areas, subregions contain putative principal neurons, diagrammed as circles. Shades of green surrounding the circles indicate the density of ChR-EYFP ${ }^{+}$axons (scale on the bottom left); ChR2-EYFP density values are expressed as the percentage of the average density in the NAc shell (100\%). Connections to the different projection areas are shown as black arrows, with relative strengths indicated by the thickness of the arrows and the incidence of connections indicated by gray shading of the circles ( $100 \%$ white to $0 \%$ black). In the circles, the percentage of connections found is above and average strength of the connections below (numbers are the same as in Fig. 7A). DA, Dopamine; GLU, glutamate.

icant positive correlation $(r=0.85)$ that was significant $\left(F_{(1,4)}=\right.$ $10.558 ; p=0.048)$. Therefore, the density of the dopaminergic projections predicted the incidence and strength of glutamatergic connections in all connected forebrain regions except ERC islands, suggesting that ERC island connections are different from the other dopamine neuron glutamatergic connections.

\section{Discussion}

We visualized dopamine neuron axons in the forebrain and analyzed the incidence and strength of their glutamatergic connections to putative principal neurons (Fig. 9). Dopamine neurons make widespread glutamatergic connections in the forebrain. We found previously undescribed connections in the CeN, CIN, and ERC. Dopamine neurons made the strongest glutamatergic connections to pyramidal neurons in ERC islands, stronger than predicted by the density of ChR2-EYFP ${ }^{+}$axons, suggesting that their connectivity is distinctly different from connectivity in other projections. This is the first systematic analysis of dopamine neuron glutamatergic connections to forebrain target areas and the first phase in the determination of the dopamine neuron functional connectome.

\section{ChR2-EYFP transduction of dopamine neurons}

Under the control of the DAT promoter, most dopamine neurons were transduced with ChR2-EYFP. Because DAT expression is lower in the medial ventral midbrain (Li et al., 2013) and in PFC-projecting dopamine neurons (Sesack et al., 1998; Lammel et al., 2008), this could have resulted in an underestimate of glutamatergic connections in that region. However, viral injections made in the VTA had similar transduction efficacy in medial and lateral VTA, so the weaker DAT promoter activity in medial VTA dopamine neurons was apparently still sufficient to drive ChR2EYFP expression in medial VTA dopamine neurons projecting to the PFC.

In extrastriatal projection areas, some $\mathrm{ChR} 2-\mathrm{EYFP}^{+}$axons were $\mathrm{TH}^{-}$. Such axons might be dopamine neuron axons that are glutamatergic and not dopaminergic, consistent with segregation of release sites (Hattori et al., 1991; Sulzer et al., 1998; Zhang et al., 2015). However, $\mathrm{ChR} 2-\mathrm{EYFP}^{+} / \mathrm{TH}^{-}$axons were also seen in the BLA, where we found no glutamatergic connections; it is possible that these axons simply express $\mathrm{TH}$ at levels below the immunohistochemical detection threshold or are GABAergic (Tritsch et al., 2012). ChR2-EYFP ${ }^{-} / \mathrm{TH}^{+}$axons seen in the PFC, hippocampus, and amygdala likely arise from nontargeted dopamine neurons or noradrenergic neurons.

Dopamine neuron glutamatergic connections in the striatum All SPNs in the NAc shell and OT without exception receive dopamine neuron glutamatergic input, highlighting these two regions as the striatal glutamate cotransmission hotspots. Anatomical studies in the rodent NAc, however, find few or no release sites with colocalized TH and VGLUT2 (Bérubé-Carrière et al., 2009; Moss et al., 2011) that would mediate corelease. Because individual glutamatergic synaptic varicosities can elicit synaptic responses of $\sim 10 \mathrm{pA}$ (in the hippocampus; Auger and Marty, 2000), only one release site would be required to mediate a functional excitatory connection; moreover, such connections would be daunting to find given that individual dopamine neurons innervate $\sim 4 \%$ of the striatal volume and may connect to $\sim 75,000$ postsynaptic neurons (Matsuda et al., 2009). The difficulty in finding anatomic evidence for corelease could also be due to segregation of dopamine and glutamate release sites (Zhang et al., 2015).

Moving dorsolaterally from the NAc shell to the core, glutamatergic inputs declined slightly and then were absent in the medial dStr, consistent with the medial-to-lateral topography of VGLUT2 expression in mouse ventral midbrain DA neurons (Yamaguchi et al., 2015). Because some DA neuron inputs to medial dStr arise from the VTA (Björklund and Dunnett, 2007), these data suggest that VTA DA neurons projecting to the dStr do not mediate glutamate cotransmission. Tritsch et al. (2012) found small glutamatergic connections to dStr SPNs, which we and others have not observed (Stuber et al., 2010; Chuhma et al., 2014); this may be due to more lateral viral injections, recording in more lateral dStr, or the use of younger mice (as dopamine neuron VGLUT2 expression undergoes developmental downregulation; Bérubé-Carrière et al., 2009).

\section{Dopamine neuron glutamatergic connections beyond the striatum}

In the amygdala, we found glutamatergic connections in CeA but not the BLA despite comparable densities of ChR2-EYFP ${ }^{+}$axons, indicating that the differences in connectivity were not due to differential innervation of the nuclei. Taylor et al. (2014) recently reported that nearly all dopamine neurons innervating the CeA coexpress VGLUT2. Our findings are consistent with this observation and further reveal that glutamatergic connections to the amygdala specifically target CeA and not BLA neurons. Ultrastructural studies report a higher incidence of $\mathrm{TH}^{+}$ asymmetric - presumably glutamatergic — synapses in the CeA 
than BLA (Asan, 1997). This suggests that single CeA dopamine neuron terminals corelease glutamate and dopamine, unlike in the NAc shell, where symmetrical (dopaminergic) and asymmetrical (glutamatergic) synapses appear to be segregated in dopamine neuron axons (Zhang et al., 2015).

We found the strongest glutamatergic connections in dopamine islands in ERC layers II/III (Hevner and Wong-Riley, 1992), which receive a dense dopamine innervation (Hökfelt et al., 1974; Fallon et al., 1978). Consistent with this, VTA (but not SN) dopamine neurons that express VGLUT2 innervate the ERC (Swanson, 1982). In contrast, ChR2-EYFP ${ }^{+} / \mathrm{TH}^{+}$axons were sparse in the ERC matrix, where no glutamatergic connections were found. ERC island connections stood out as being far stronger than predicted by dopamine neuron fiber density, indicating that DA neuron connectivity in ERC islands differs from other regions and likely involves multiple innervation of defined target neurons.

In the hippocampus, ChR2-EYFP ${ }^{+} / \mathrm{TH}^{+}$axons were sparse in the presubiculum and subiculum and extremely rare in CA1, where no glutamatergic connections were found. Although initial reports indicated the presence of a dopamine innervation in the hippocampus (Scatton et al., 1980; Gasbarri et al., 1994), these studies used large deposits of retrograde tracers that extended beyond the DG and pyramidal cell layers and would have been subject to uptake by fibers of passage. Verney et al. (1985) observed hippocampal dopamine fibers, revealed by accumulation of radiolabeled dopamine, but noted that these were mainly present in the presubiculum and subiculum, with only rare fibers in the pyramidal cell layers, mirroring our observations. Our anatomical data do not support the presence of a significant VTAderived dopamine innervation of the hippocampus. Indeed, most dopamine release in the hippocampus appears to arise from noradrenergic axons (Smith and Greene, 2012).

Midbrain dopamine neurons innervate several cortical regions, including the PFC and CIN, but we found only one glutamatergic connection. Mesocortical glutamatergic connections appear to arise from glutamate-only VTA neurons (Yamaguchi et al., 2011; Gorelova et al., 2012). However, some VGLUT2 expression in PFC dopamine axons has been reported in retrograde tracing studies (Gorelova et al., 2012) and $\sim 25 \%$ of dopamine neurons projecting to the PFC coexpress VGLUT2 (Yamaguchi et al., 2011; Taylor et al., 2014). The relatively high incidence of VGLUT2 coexpression in mesocortical dopamine neurons contrasts with the paucity of glutamatergic connections to pyramidal neurons that we found, consistent with dopamine neurons making glutamatergic connections to interneurons (Sesack et al., 1995).

\section{Functional implications}

Dopamine neurons make excitatory glutamatergic connections to neurons in forebrain regions that vary widely in strength, adding new complexity to dopamine neuron actions. In the NAc shell and OT, dopamine neuron glutamate connections can drive SPNs to fire if the cells are already modestly depolarized (Tecuapetla et al., 2010), suggesting that dopamine neuron EPSCs would only drive firing coincident with other glutamatergic inputs. In contrast, we and others have reported that dopamine neuron connections to cholinergic interneurons are nearly an order of magnitude stronger and do drive the cells to fire (Chuhma et al., 2014; Wieland et al., 2014), making it more likely that dopamine neurons exert fast control of vStr activity via cholinergic interneurons. Functionally, these temporally precise glutamatergic connections have the necessary physiological sig- nature to convey information about dopamine-dependent salience signals to the vStr and to facilitate associative learning (Zweifel et al., 2009). The CeA glutamatergic connections are weaker than those found in NAc SPNs. Weaker connections might identify release sites where glutamate cotransport potentiates dopamine release through vesicular synergy by increasing the packing of dopamine into vesicles (El Mestikawy et al., 2011; Hnasko and Edwards, 2012). Because the dopaminergic projections to the CeA and BLA are of similar densities and glutamate cotransmission is only seen in the CeA, vesicular synergy would specifically potentiate dopaminergic transmission in the CeA, and not in the BLA, and this might regulate the dopaminergic modulation of CeA-dependent fear responses (Paré et al., 2004). Remarkably, dopamine neurons make the strongest glutamatergic connections in ERC islands. Lateral ERC cells are involved in processing the salience of environmental nonspatial information (Knierim et al., 2014); dopamine neuron glutamatergic connections could signal salient events and gate ERC inputs to the hippocampus. Because dopamine neuron axons are so sparse in the hippocampus, memory functions attributed to the hippocampusVTA loop (Lisman and Grace, 2005) may involve dopamine neuron glutamatergic connections to the ERC. This functional connectome analysis is the first systematic analysis of dopamine neuron glutamatergic connections to forebrain regions. Mapping these connections-extending to nonprincipal postsynaptic neurons and other transmitters-will be crucial for improving our understanding of the behavioral functions of dopamine neurons, including how they are differentially involved in neuropsychiatric disorders and how they may be differentially targeted pharmacologically for therapeutic benefit.

\section{References}

Abramoff M, Magalhaes P, Ram S (2004) Image processing with ImageJ. Biophotonics International 11:36-42.

Adrover MF, Shin JH, Alvarez VA (2014) Glutamate and dopamine transmission from midbrain dopamine neurons share similar release properties but are differentially affected by cocaine. J Neurosci 34:3183-3192. CrossRef Medline

Asan E (1997) Ultrastructural features of tyrosine-hydroxylase-immunoreactive afferents and their targets in the rat amygdala. Cell Tissue Res 288:449469. CrossRef Medline

Atasoy D, Aponte Y, Su HH, Sternson SM (2008) A FLEX switch targets Channelrhodopsin-2 to multiple cell types for imaging and long-range circuit mapping. J Neurosci 28:7025-7030. CrossRef Medline

Auger C, Marty A (2000) Quantal currents at single-site central synapses. J Physiol 526:3-11. CrossRef Medline

Bäckman CM, Malik N, Zhang Y, Shan L, Grinberg A, Hoffer BJ, Westphal H, Tomac AC (2006) Characterization of a mouse strain expressing Cre recombinase from the $3^{\prime}$ untranslated region of the dopamine transporter locus. Genesis 44:383-390. CrossRef Medline

Bentivoglio M, Morellis M (2005) The organization and circuits of mesencephalic dopaminergic neurons and the distribution of dopamine receptors in the brain. In: Handbook of chemical neuroanatomy, pp 1-107. New York: Elsevier.

Berger B, Gaspar P, Verney C (1991) Dopaminergic innervation of the cerebral cortex: unexpected differences between rodents and primates. Trends Neurosci 14:21-27. CrossRef Medline

Bérubé-Carrière N, Riad M, Dal Bo G, Lévesque D, Trudeau LE, Descarries L (2009) The dual dopamine-glutamate phenotype of growing mesencephalic neurons regresses in mature rat brain. J Comp Neurol 517:873891. CrossRef Medline

Björklund A, Dunnett SB (2007) Fifty years of dopamine research. Trends Neurosci 30:185-187. CrossRef Medline

Björklund A, Dunnett SB (2007) Dopamine neuron systems in the brain: an update. Trends Neurosci 30:194-202. CrossRef Medline

Bubser M, Scruggs JL, Young CD, Deutch AY (2000) The distribution and origin of the calretinin-containing innervation of the nucleus accumbens of the rat. Eur J Neurosci 12:1591-1598. CrossRef Medline 
Busse B, Smith S (2013) Automated analysis of a diverse synapse population. PLoS Comput Biol 9:e1002976. CrossRef Medline

Chuhma N, Zhang H, Masson J, Zhuang X, Sulzer D, Hen R, Rayport S (2004) Dopamine neurons mediate a fast excitatory signal via their glutamatergic synapses. J Neurosci 24:972-981. CrossRef Medline

Chuhma N, Mingote S, Moore H, Rayport S (2014) Dopamine neurons control striatal cholinergic neurons via regionally heterogeneous dopamine and glutamate signaling. Neuron 81:901-912. CrossRef Medline

Cohen JY, Haesler S, Vong L, Lowell BB, Uchida N (2012) Neuron-typespecific signals for reward and punishment in the ventral tegmental area. Nature 482:85-88. CrossRef Medline

Dal Bo G, St-Gelais F, Danik M, Williams S, Cotton M, Trudeau LE (2004) Dopamine neurons in culture express VGLUT2 explaining their capacity to release glutamate at synapses in addition to dopamine. J Neurochem 88:1398-1405. CrossRef Medline

Descarries L, Lemay B, Doucet G, Berger B (1987) Regional and laminar density of the dopamine innervation in adult rat cerebral cortex. Neuroscience 21:807-824. CrossRef Medline

El Mestikawy S, Wallén-Mackenzie A, Fortin GM, Descarries L, Trudeau LE (2011) From glutamate co-release to vesicular synergy: vesicular glutamate transporters. Nat Rev Neurosci 12:204-216. Medline

Everitt BJ, Robbins TW (2013) From the ventral to the dorsal striatum: devolving views of their roles in drug addiction. Neurosci Biobehav Rev 37:1946-1954. CrossRef Medline

Fallon JH, Koziell DA, Moore RY (1978) Catecholamine innervation of the basal forebrain. II. Amygdala, suprarhinal cortex and entorhinal cortex. J Comp Neurol 180:509-532. CrossRef Medline

Freedman LJ, Cassell MD (1994) Distribution of dopaminergic fibers in the central division of the extended amygdala of the rat. Brain Res 633:243252. CrossRef Medline

Gasbarri A, Packard MG, Campana E, Pacitti C (1994) Anterograde and retrograde tracing of projections from the ventral tegmental area to the hippocampal formation in the rat. Brain Res Bull 33:445-452. CrossRef Medline

Gorelova N, Mulholland PJ, Chandler LJ, Seamans JK (2012) The glutamatergic component of the mesocortical pathway emanating from different subregions of the ventral midbrain. Cereb Cortex 22:327-336. CrossRef Medline

Gunaydin LA, Grosenick L, Finkelstein JC, Kauvar IV, Fenno LE, Adhikari A, Lammel S, Mirzabekov JJ, Airan RD, Zalocusky KA, Tye KM, Anikeeva P, Malenka RC, Deisseroth K (2014) Natural neural projection dynamics underlying social behavior. Cell 157:1535-1551. CrossRef Medline

Hattori T, Takada M, Moriizumi T, Van der Kooy D (1991) Single dopaminergic nigrostriatal neurons form two chemically distinct synaptic types: possible transmitter segregation within neurons. J Comp Neurol 309: 391-401. CrossRef Medline

Hevner RF, Wong-Riley MT (1992) Entorhinal cortex of the human, monkey, and rat: metabolic map as revealed by cytochrome oxidase. J Comp Neurol 326:451-469. CrossRef Medline

Hnasko TS, Edwards RH (2012) Neurotransmitter corelease: mechanism and physiological role. Annu Rev Physiol 74:225-243. CrossRef Medline

Hnasko TS, Chuhma N, Zhang H, Goh GY, Sulzer D, Palmiter RD, Rayport S, Edwards RH (2010) Vesicular glutamate transport promotes dopamine storage and glutamate corelease in vivo. Neuron 65:643-656. CrossRef Medline

Hnasko TS, Hjelmstad GO, Fields HL, Edwards RH (2012) Ventral tegmental area glutamate neurons: electrophysiological properties and projections. J Neurosci 32:15076-15085. CrossRef Medline

Hökfelt T, Fuxe K, Johansson O, Ljungdahl A (1974) Pharmacohistochemical evidence of the existence of dopamine nerve terminals in the limbic cortex. Eur J Pharmacol 25:108-112. CrossRef Medline

Ishikawa M, Otaka M, Neumann PA, Wang Z, Cook JM, Schlüter OM, Dong Y, Huang YH (2013) Exposure to cocaine regulates inhibitory synaptic transmission from the ventral tegmental area to the nucleus accumbens. J Physiol 591:4827-4841. CrossRef Medline

Kawano M, Kawasaki A, Sakata-Haga H, Fukui Y, Kawano H, Nogami H, Hisano S (2006) Particular subpopulations of midbrain and hypothalamic dopamine neurons express vesicular glutamate transporter 2 in the rat brain. J Comp Neurol 498:581-592. CrossRef Medline

Knierim JJ, Neunuebel JP, Deshmukh SS (2014) Functional correlates of the lateral and medial entorhinal cortex: objects, path integration and local- global reference frames. Philos Trans R Soc Lond B Biol Sci 369:20130369. Medline

Kuepper R, Skinbjerg M, Abi-Dargham A (2012) The dopamine dysfunction in schizophrenia revisited: new insights into topography and course. Handb Exp Pharmacol 212:1-26. CrossRef Medline

Lammel S, Hetzel A, Häckel O, Jones I, Liss B, Roeper J (2008) Unique properties of mesoprefrontal neurons within a dual mesocorticolimbic dopamine system. Neuron 57:760-773. CrossRef Medline

Lammel S, Steinberg EE, Földy C, Wall NR, Beier K, Luo L, Malenka RC (2015) Diversity of transgenic mouse models for selective targeting of midbrain dopamine neurons. Neuron 85:429-438. CrossRef Medline

Li X, Qi J, Yamaguchi T, Wang HL, Morales M (2013) Heterogeneous composition of dopamine neurons of the rat A10 region: molecular evidence for diverse signaling properties. Brain Struct Funct 218:1159-1176. CrossRef Medline

Lisman JE, Grace AA (2005) The hippocampal-VTA loop: Controlling the entry of information into long-term memory. Neuron 46:703-713. CrossRef Medline

Lüscher C, Malenka RC (2011) Drug-evoked synaptic plasticity in addiction: from molecular changes to circuit remodeling. Neuron 69:650-663. CrossRef Medline

Matsuda W, Furuta T, Nakamura KC, Hioki H, Fujiyama F, Arai R, Kaneko T (2009) Single nigrostriatal dopaminergic neurons form widely spread and highly dense axonal arborizations in the neostriatum. J Neurosci 29:444-453. CrossRef Medline

Mendez JA, Bourque MJ, Dal Bo G, Bourdeau ML, Danik M, Williams S, Lacaille JC, Trudeau LE (2008) Developmental and target-dependent regulation of vesicular glutamate transporter expression by dopamine neurons. J Neurosci 28:6309-6318. CrossRef Medline

Morales M, Root DH (2014) Glutamate neurons within the midbrain dopamine regions. Neuroscience 282C:60-68. CrossRef Medline

Moss J, Ungless MA, Bolam JP (2011) Dopaminergic axons in different divisions of the adult rat striatal complex do not express vesicular glutamate transporters. Eur J Neurosci 33:1205-1211. CrossRef Medline

Paré D, Quirk GJ, Ledoux JE (2004) New vistas on amygdala networks in conditioned fear. J Neurophysiol 92:1-9. CrossRef Medline

Paxinos G, Franklin K (2001) The mouse brain in stereotaxic coordinates. San Diego: Academic.

Phillipson OT (1979) A Golgi study of the ventral tegmental area of Tsai and interfascicular nucleus in the rat. J Comp Neurol 187:99-115. CrossRef Medline

Salamone JD, Correa M (2012) The mysterious motivational functions of mesolimbic dopamine. Neuron 76:470-485. CrossRef Medline

Scatton B, Simon H, Le Moal M, Bischoff S (1980) Origin of dopaminergic innervation of the rat hippocampal formation. Neurosci Lett 18:125-131. CrossRef Medline

Sesack SR, Snyder CL, Lewis DA (1995) Axon terminals immunolabeled for dopamine or tyrosine hydroxylase synapse on GABA-immunoreactive dendrites in rat and monkey cortex. J Comp Neurol 363:264-280. CrossRef Medline

Sesack SR, Hawrylak VA, Matus C, Guido MA, Levey AI (1998) Dopamine axon varicosities in the prelimbic division of the rat prefrontal cortex exhibit sparse immunoreactivity for the dopamine transporter. J Neurosci 18:2697-2708. Medline

Smith CC, Greene RW (2012) CNS dopamine transmission mediated by noradrenergic innervation. J Neurosci 32:6072-6080. CrossRef Medline

Stuber GD, Hnasko TS, Britt JP, Edwards RH, Bonci A (2010) Dopaminergic terminals in the nucleus accumbens but not the dorsal striatum corelease glutamate. J Neurosci 30:8229-8233. CrossRef Medline

Sulzer D, Joyce MP, Lin L, Geldwert D, Haber SN, Hattori T, Rayport S (1998) Dopamine neurons make glutamatergic synapses in vitro. J Neurosci 18:4588-4602. Medline

Swanson LW (1982) The projections of the ventral tegmental area and adjacent regions: a combined fluorescent retrograde tracer and immunofluorescence study in the rat. Brain Res Bull 9:321-353. CrossRef Medline

Taylor SR, Badurek S, Dileone RJ, Nashmi R, Minichiello L, Picciotto MR (2014) GABAergic and glutamatergic efferents of the mouse ventral tegmental area. J Comp Neurol 522:3308-3334. CrossRef Medline

Tecuapetla F, Patel JC, Xenias H, English D, Tadros I, Shah F, Berlin J, Deisseroth K, Rice ME, Tepper JM, Koos T (2010) Glutamatergic signaling by mesolimbic dopamine neurons in the nucleus accumbens. J Neurosci 30:7105-7110. CrossRef Medline 
Tritsch NX, Ding JB, Sabatini BL (2012) Dopaminergic neurons inhibit striatal output through non-canonical release of GABA. Nature 490:262-266. CrossRef Medline

Trudeau LE, Hnasko TS, Wallén-Mackenzie A, Morales M, Rayport S, Sulzer D (2014) The multilingual nature of dopamine neurons. Prog Brain Res 211:141-164. CrossRef Medline

Tsai HC, Zhang F, Adamantidis A, Stuber GD, Bonci A, de Lecea L, Deisseroth $\mathrm{K}$ (2009) Phasic firing in dopaminergic neurons is sufficient for behavioral conditioning. Science 324:1080-1084. CrossRef Medline

Verney C, Baulac M, Berger B, Alvarez C, Vigny A, Helle KB (1985) Morphological evidence for a dopaminergic terminal field in the hippocampal formation of young and adult rat. Neuroscience 14:1039-1052. CrossRef Medline

Wang LP, Li F, Wang D, Xie K, Wang D, Shen X, Tsien JZ (2011) NMDA receptors in dopaminergic neurons are crucial for habit learning. Neuron 72:1055-1066. CrossRef Medline

Wieland S, Du D, Oswald MJ, Parlato R, Köhr G, Kelsch W (2014) Phasic dopaminergic activity exerts fast control of cholinergic interneuron firing via sequential NMDA, D2, and D1 receptor activation. J Neurosci 34: 11549-11559. CrossRef Medline
Yamaguchi T, Wang HL, Li X, Ng TH, Morales M (2011) Mesocorticolimbic glutamatergic pathway. J Neurosci 31:8476-8490. CrossRef Medline

Yamaguchi T, Qi J, Wang HL, Zhang S, Morales M (2015) Glutamatergic and dopaminergic neurons in the mouse ventral tegmental area. Eur J Neurosci 41:760-772. CrossRef Medline

Yetnikoff L, Lavezzi HN, Reichard RA, Zahm DS (2014) An update on the connections of the ventral mesencephalic dopaminergic complex. Neuroscience 282C:23-48. CrossRef Medline

Zhang S, Qi J, Li X, Wang HL, Britt JP, Hoffman AF, Bonci A, Lupica CR, Morales M (2015) Dopaminergic and glutamatergic microdomains in a subset of rodent mesoaccumbens axons. Nat Neurosci 18:386-392. CrossRef Medline

Zweifel LS, Parker JG, Lobb CJ, Rainwater A, Wall VZ, Fadok JP, Darvas M, Kim MJ, Mizumori SJ, Paladini CA, Phillips PE, Palmiter RD (2009) Disruption of NMDAR-dependent burst firing by dopamine neurons provides selective assessment of phasic dopamine-dependent behavior. Proc Natl Acad Sci U S A 106:7281-7288. CrossRef Medline 